\title{
PKC $\zeta$ regulates Notch receptor routing and activity in a Notch signaling-dependent manner
}

\author{
Marika Sjöqvist ${ }^{1,2,{ }^{*}}$, Daniel Antfolk ${ }^{1,2,}{ }^{*}$, Saima Ferraris ${ }^{2}$, Vilma Rraklli $^{3}$, Cecilia Haga ${ }^{1,2}$, Christian Antila ${ }^{1,2}$, \\ Anders Mutvei ${ }^{4}$, Susumu Y Imanishi ${ }^{1}$, Johan Holmberg ${ }^{3,4}$, Shaobo Jin ${ }^{4}$, John E Eriksson ${ }^{1,2}$, Urban Lendahl ${ }^{4}$, \\ Cecilia Sahlgren ${ }^{1,2,5}$
}

${ }^{I}$ Turku Centre for Biotechnology, University of Turku and Åbo Akademi University, 20520 Turku, Finland; ${ }^{2}$ Department of Biosciences, Åbo Akademi University, 20520 Turku, Finland; ${ }^{3}$ Ludwig Institute for Cancer Research, Karolinska Institute, Box 240, SE17177 Stockholm, Sweden; ${ }^{4}$ Department of Cell and Molecular Biology, Karolinska Institutet, SE-171 77 Stockholm, Sweden; ${ }^{5}$ Department of Biomedical Engineering, Technical University of Eindhoven, 2612 Eindhoven, The Netherlands

Activation of Notch signaling requires intracellular routing of the receptor, but the mechanisms controlling the distinct steps in the routing process is poorly understood. We identify $\mathrm{PKC} \zeta$ as a key regulator of Notch receptor intracellular routing. When $\mathrm{PKC} \zeta$ was inhibited in the developing chick central nervous system and in cultured myoblasts, Notch-stimulated cells were allowed to undergo differentiation. PKC $\zeta$ phosphorylates membrane-tethered forms of Notch and regulates two distinct routing steps, depending on the Notch activation state. When Notch is activated, $\mathrm{PKC} \zeta$ promotes re-localization of Notch from late endosomes to the nucleus and enhances production of the Notch intracellular domain, which leads to increased Notch activity. In the non-activated state, PKC $\zeta$ instead facilitates Notch receptor internalization, accompanied with increased ubiquitylation and interaction with the endosomal sorting protein Hrs. Collectively, these data identify $\mathrm{PKC} \zeta$ as a key regulator of Notch trafficking and demonstrate that distinct steps in intracellular routing are differentially modulated depending on Notch signaling status.

Keywords: atypical PKC; endocytosis; Notch signaling; lysosome; Hrs

Cell Research (2014) 24:433-450. doi:10.1038/cr.2014.34; published online 25 March 2014

\section{Introduction}

The Notch pathway regulates a cell-cell communication and thereby is important for control of cell differentiation in many different cell types. The complex proteolytic processing and intracellular routing of the Notch receptor are two cardinal features of the pathway $[1,2]$. Notch signaling is initiated by the interaction between the cell-bound Notch receptors and transmembrane ligands on juxtaposed cells. This leads to two proteolytic cleavages of the Notch receptor: an extracellular site 2 (S2) cleavage conducted by ADAM metalloproteases, which generates a truncated transmembrane receptor form, Notch Extracellular Truncation (NEXT), and a

*These two authors contributed equally to this work.

Correspondence: Cecilia Sahlgren

Email: cecilia.sahlgren@btk.fi

Received 8 May 2013; revised 17 December 2013; accepted 20 December 2013; published online 25 March 2014 further processing of NEXT by the $\gamma$-secretase complex in the membrane. The second cleavage (at site 3, S3 cleavage) generates the Notch intracellular domain (Notch ICD or NICD), which translocates to the nucleus, interacts with the DNA-binding protein CSL (CBF1, Suppressor of Hairless, Lag-1) and activates expression of Notch downstream genes.

In contrast to the relatively simple molecular architecture, it is becoming increasingly apparent that regulation of Notch signaling is more complex and that endocytosis and trafficking of the Notch receptor are important constituents of the pathway $[1,2]$. It is well known that Notch receptors can be internalized, but the underlying mechanisms and effects of receptor internalization on Notch signaling activity are poorly understood [3]. There are several reports advocating that endocytosis promotes Notch activation [4-7], while other studies suggest that intracellular trafficking exerts a negative effect [812]. Similarly, there are conflicting views on where S3 processing occurs. A number of reports indicate that $\mathrm{S} 3$ 
cleavage occurs after receptor internalization $[4,7,12-$ 14], while other studies suggest that it may occur at the cell surface [12]. Furthermore, S3 processing at the cell surface versus in the endosomes may yield distinct N-termini on the resulting NICD, and may endow them with distinct properties [15]. Proper routing of the internalized Notch receptor may also be important for preventing ligand-independent activation, and Notch signaling defects are indeed linked to impaired endocytic trafficking and endosome acidification [4, 16]. The internalization step appears to be controlled by monoubiquitylation of the Notch receptor at the cell surface [4], followed by a deubiquitylation event, which is required for signaling activation [17]. Deltex, an E3 ubiquitin ligase, is a regulator of Notch internalization and processing, although whether it functions to enhance or reduce Notch signaling appears to be cell context-dependent [18-20]. Compromised sorting from early endosomes to multivesicular bodies (MVBs) or lysosomes, resulting from ESCRT/ lethal giant larvae mutations in Drosophila, affects the Notch signaling [21], and Numb and Itch likely regulate postendocytic sorting events [22] (for review see [1, 3, 23]).

These findings point to a complex and dynamic regulation of Notch receptor intracellular routing, but it remains unknown as to how the distinct steps in the routing process from cell surface via internalization into endosomes and onwards to the nucleus are controlled. It is likely that additional proteins are involved in the control of Notch trafficking, and that regulation of routing modulates the Notch signaling output. Atypical protein kinase $\mathrm{C}(\mathrm{aPKC})$ may be an interesting candidate for control of Notch receptor intracellular trafficking and function, as there is an emerging view that aPKCs play a key role both in regulation of protein trafficking and in various differentiation processes. aPKCs play critical roles in cell polarization [24, 25], asymmetric cell division [26, 27] and migration [28-30], and also link cell polarity cues to differentiation [26, 27, 31-34]. aPKCs are critical regulators of the organization of the apical-basal axis in epithelial cells, a process in which aPKC functions together with PAR-3 and PAR-6 in a complex, and this PAR-3/ PAR-6/aPKC complex is pivotal for establishing cellular polarity and organizing cellular junctions [35-38]. aPKC also regulates the Cdk5 kinase during myoblast differentiation [39] and PAR1-aPKC antagonism regulates neurogenesis through modulation of Notch signaling [40]. PAR1 (negatively regulated by aPKC) acts on the E3 ubiquitin ligase Mindbomb to regulate Notch ligands in the signal-sending cells. Polarity proteins are key regulators of endocytic trafficking $[28,41]$, and can function to segregate proteins to the apical or basal side through regulation of intracellular trafficking [42].

In this report, we unravel a novel role of atypical $\mathrm{PKC} \zeta(\mathrm{aPKC} \zeta)$ in control of intracellular localization of Notch1 and Notch signaling output. We demonstrate that inhibition of aPKC $\zeta$ reduces the ability of Notch to keep cells undifferentiated in the chick central nervous system (CNS) in vivo and in myogenic progenitors in vitro. aPKC $\zeta$ interacts with and phosphorylates membranetethered but not cytoplasmic forms of Notch1, and controls Notch1 trafficking with different outcomes depending on the Notch activation state. When Notch signaling is not activated, aPKC $\zeta$ regulates the transition of Notch from cell surface and the secretory Golgi/ER pathway to intracellular vesicles. In contrast, when Notch signaling is active, $\mathrm{aPKC} \zeta$ governs the routing from intracellular vesicles to the cell nucleus, leading to augmented activation of the Notch signaling pathway. These data identify aPKC $\zeta$ as a key regulator of intracellular localization of Notch receptor and Notch signaling output, and show that intracellular routing of the Notch receptor is differentially modulated depending on the activity status of the Notch signaling pathway itself.

\section{Results}

Inhibition of aPKCל reduces the capacity of Notch to negatively regulate neuronal differentiation in the developing CNS

It is well established that Notch signaling in many cellular contexts inhibits differentiation and maintains cells in a more undifferentiated state. This has been extensively explored in the developing chick CNS where expression of NICD maintains CNS progenitor cells close to the ventricle and inhibits their maturation to early, Tuj1-positive neurons located at the marginal zone of the neural tube [43]. We tested whether PKC $\zeta$ influenced Notch-mediated block of neuronal differentiation in the chick CNS. To this end, we engineered a membranetethered activated form of Notch1, Notch $1 \Delta \mathrm{E}$, that was Myc-tagged and linked to a nuclear form of EGFP via an IRES sequence to trace expression. We confirmed that the construct, CAG-Notch $1 \Delta$ E-Myc-IRES-EGFP, was expressed and that the expression indeed resulted in robust activation of a reporter construct containing 12 CSL-binding motifs $(12 \times$ CSL-dsRED) [44] (Figure 1A1C). To explore a possible role of $\mathrm{PKC} \zeta$ in regulating Notch activity and control of stem cell differentiation, we next combined expression of CAG-Notch $1 \Delta \mathrm{E}-\mathrm{Myc}-$ IRES-EGFP with pharmacological inhibition of PKCל activity using a pseudosubstrate peptide (PS; Myr-SIYRRGARRWRKL). The inhibitor was injected into the ventricular space of $\mathrm{HH}$ stage 10 chick embryos and CAG- 
Notch1 $\Delta$ E-Myc-IRES-EGFP was electroporated. Expression of CAG-Notch1 $\triangle \mathrm{E}-\mathrm{Myc}$-IRES-EGFP in the absence of inhibitors led to a marked reduction in the number of Tuj1-positive cells compared with the other side of

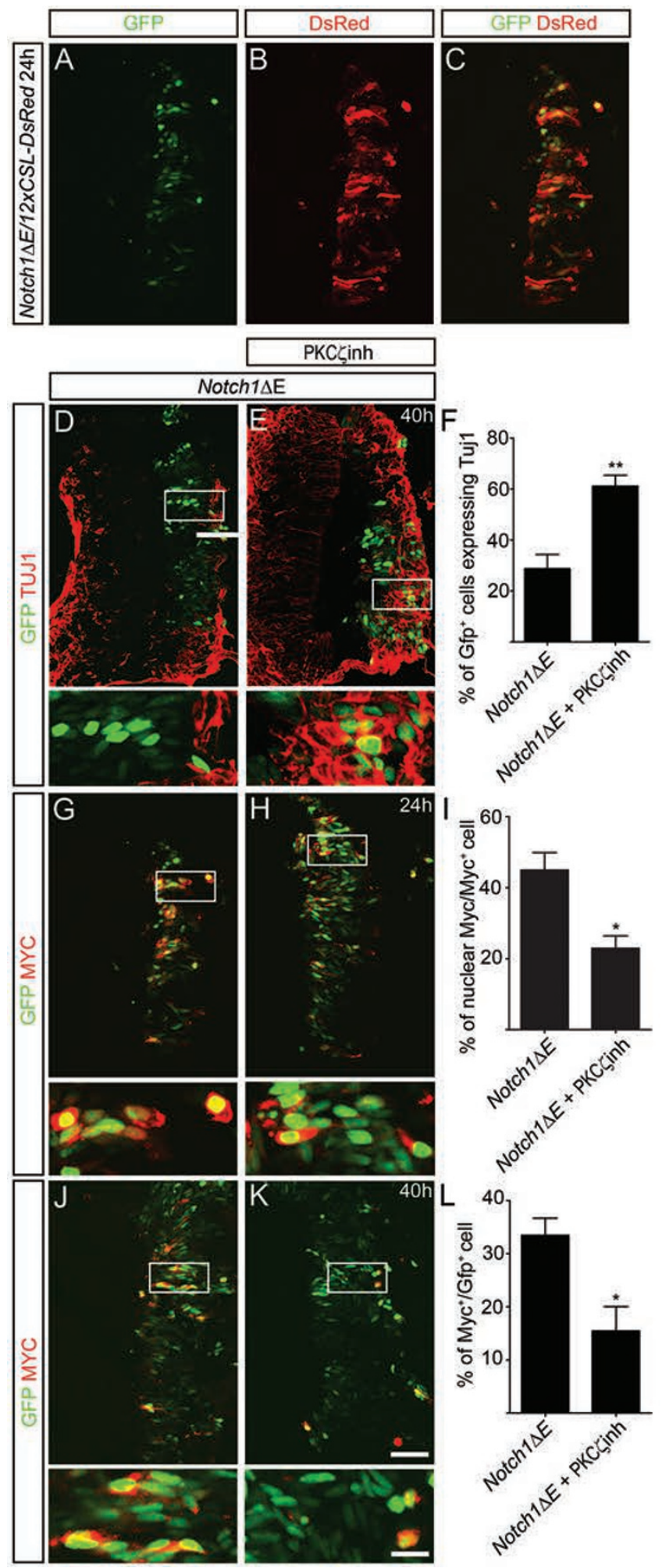

the neural tube without Notch $1 \Delta \mathrm{E}$ overexpression, and a localization of the Notch-expressing cells close to the ventricle (Figure 1D and1F), which is in keeping with previous observations [43]. In contrast, when CAGNotch1 $\Delta$ E-Myc-IRES-EGFP was expressed in the presence of PKC $\zeta$ inhibitor, we observed a partial shift of Notch-expressing cells (visualized by EGFP) to the marginal zone of the neural tube, and an increased overlap between EGFP and Tuj1 expression (Figure 1E). This suggests that the activity of Notch was reduced, allowing electroporated cells to differentiate despite expressing an activated form of Notch. However, the pharmacological inhibition of PKC $\zeta$ was not sufficient to significantly reduce the $12 \times \mathrm{CSL}$-dsRED reporter activity (data not shown), which is likely an effect of the expression of very high levels of Notch $1 \Delta \mathrm{E}$ following electroporation.

Embryos receiving the $\mathrm{PKC} \zeta$ inhibitor exhibited an altered intracellular localization of Notch1 (Figure 1G1I, Supplementary information, Figure S1A and S1B). In the absence of the inhibitor, Notch1, visualized by Myc immunostaining, was evenly distributed between the nucleus and the cytoplasm, where it was expressed in a speckled pattern (Figure 1G-1I, Supplementary informa-

Figure 1 Regulation of Notch1 by $\mathrm{PKC} \zeta$ affects in vivo neuronal differentiation, protein localization and expression. (A-C) Cells co-electroporated with CAG-Notch1 E-myc-IRES-EGFP and the $12 \times C S L-D s R e d$ reporter expressed eGFP (nuclear because CAG-Notch1 $\triangle E$-myc-IRES-EGFP contains a nuclear localization signal (NLS)) (A) and DsRed (B), which overlay in C, showing that Notch $1 \triangle \mathrm{E}$ efficiently activates Notch signaling within 24 h. (D) Cells expressing CAG-Notch1 $\triangle E$-myc-IRES-EGFP (green) did not show staining for the neuronal marker Tuj1 (red, inset) and showed reduced migration out to the marginal zone, 40 $\mathrm{h}$ after electroporation. (E) In embryos injected with the aPKC inhibitor, Notch $1 \Delta \mathrm{E}$-expressing cells (green, inset) exhibited increased expression of Tuj1 (red, inset). (F) Quantification of the ratio of $\mathrm{GFP}^{+}$cells that also expressed Tuj $140 \mathrm{~h}$ after electroporation with CAG-Notch1 $1 E$-myc-IRES-EGFP in the presence or absence of the aPKC inhibitor. (G) Twenty-four hours after electroporation, cells expressing CAG-Notch1 $\triangle E$-myc-IRESEGFP (green, inset) exhibited nuclear Myc localization in approximately half of the Myc-positive cells (red, inset). $(\mathbf{H})$ In the presence of the aPKC inhibitor, nuclear localization of Myc was significantly reduced (red, inset). (I) Quantification of the proportion of cells with nuclear-localized Myc compared to the total number of Myc-expressing cells. (J) CAG-Notch1 $1 \Delta$ E-myc-IRESEGFP-expressing cells (green, inset) retaining Myc (red, inset) immunoreactivity $40 \mathrm{~h}$ post electroporation. (K) CAG-Notch1 $\Delta E-$ myc-IRES-EGFP-expressing cells (green, inset) treated with aPKC inhibitor exhibited reduced Myc immunoreactivity (red, inset) $40 \mathrm{~h}$ after electroporation. (L) Quantification of the number of GFP-expressing cells that exhibit Myc immunoreactivity. Data are represented as mean \pm SEM. ${ }^{*} P<0.05$, ${ }^{* *} P<0.01$, Student's $t$-test. Scale bars, upper $45 \mu \mathrm{m}$, lower (inset) $15 \mu \mathrm{m}$. 
tion, Figure S1A and S1B). This is indicative of a location in intracellular vesicles, which is in keeping with the established view on Notch intracellular distribution. In contrast, the presence of $\mathrm{PKC} \zeta$ inhibitor reduced the levels of nuclear Notch protein and increased the ratio of Myc immunoreactivity in the cytoplasm (Figure $1 \mathrm{H}$ and 1I).

We next examined whether Notch protein levels were affected by PKC $\zeta$ by comparing the number of cells that had at one point expressed Notch $1 \Delta \mathrm{E}$ (EGFP-expressing cells) with the number of cells that contained Notch $1 \Delta \mathrm{E}$, or its derivative NICD (Myc immunoreactivity). Forty hours after electroporation, embryos treated with PKCל inhibitor exhibited a reduction in the proportion of EGFP-expressing cells that also exhibited Myc immunoreactivity (Figure 1J-1L).

Taken together, these data indicate that blocking PKCל activity mitigates Notch-mediated blocking of neuronal differentiation. Inhibition of $\mathrm{PKC} \zeta$ also caused a partial re-localization of Notch from the nucleus to the cytoplasm and over time a reduction in the total levels of Notch protein.

aPKC interacts with membrane-tethered but not cytoplasmic forms of Notch1 and phosphorylates Notch1

To explore the mechanistic basis for the relationship between $\mathrm{PKC} \zeta$ and Notch1 in vivo (Figure 1), we first tested whether PKC $\zeta$ interacts with Notch1. The endogenous Notch1 was immunoprecipitated from non-differentiating and differentiating $\mathrm{C} 2 \mathrm{C} 12$ cells, and in both cases PKC $\zeta$ was shown to interact with Notch1 (Figure 2A). We next addressed whether the interaction was dependent on the Notch signaling status. Notch1 was immunoprecipitated before and after activation by immobilized Delta-like 1 ligand (D111) and in the presence or absence of $\gamma$-secretase inhibitor (GSI) treatment. PKC $\zeta$ interacted with both the ligand-activated and non-activated Notch1, but the interaction was stronger in GSI-treated cells when Notch1 was activated by the ligands (Figure 2B).

We next assessed whether $\mathrm{PKC} \zeta$ interacted with Notch $1 \Delta$ E. PKC $\zeta$ interacted with Notch $1 \Delta \mathrm{E}$, and like in the full-length receptor situation, GSI treatment enhanced the interaction (Figure 2C). We then addressed whether $\mathrm{PKC} \zeta$ also interacted with NICD. In contrast to the interaction observed when Notch1 was immunoprecipitated with the $\mathrm{C} 20$ antibody that recognizes all forms of Notch1 (full length, S2 and S3 cleaved forms) (Supplementary information, Figure S2), no interaction was seen when NICD was immunoprecipitated from cells transfected with Notch $1 \Delta \mathrm{E}$ using the cleaved-Notch antibody that only recognizes the S3 cleaved form (Figure 2D left and Supplementary information, Figure S2).
We further tested the interaction between $\mathrm{PKC} \zeta$ and a de novo generated NICD, which is structurally identical to the intracellular domain of Notch1, but is produced in the cytoplasm and thus never membrane-tethered. In contrast to the interaction observed with Notch $1 \Delta \mathrm{E}$, no interaction was seen between NICD and $\mathrm{PKC} \zeta$ (Figure $2 \mathrm{D}$, right and below).

To determine whether Notch1 serves as a direct enzymatic target for $\mathrm{PKC} \zeta$, we analyzed whether Notch1 immunoprecipitated from $\mathrm{C} 2 \mathrm{C} 12$ cells could be in vitro phosphorylated by recombinant $\mathrm{PKC} \zeta$. We found that Notch1 was phosphorylated by $\mathrm{PKC} \zeta$, and no phosphorylation was observed when PKC $\zeta$ was omitted (Figure $2 \mathrm{E}$ ). Mass spectrometry analysis of the phosphorylated Notch1 identified Serine (S) 1791, located in the intracellular domain, as the predominant $\mathrm{PKC} \zeta$ phosphorylation site (Supplementary information, Figure S3A). The S1791 residue is highly conserved from amphibia to human, and is present in both Notch1 and 2 (Figure 2F). The site is however not found in Drosophila or Caenorhabditis elegans and is also absent from Notch3 and 4 in vertebrates (Supplementary information, Figure S4). Mass spectrometry analysis of Notch 1 phosphorylated in vitro with $\mathrm{PKCl}$ yielded similar results (Supplementary information, Figure S3B), showing that different aPKC isoforms can phosphorylate Notch at the same residue. Taken together, these data indicate that Notch is a novel target for phosphorylation by $\mathrm{PKC} \zeta$ and that $\mathrm{PKC} \zeta$ interacts with membrane-tethered full-length and Notch $1 \Delta \mathrm{E}$ forms of the receptor but not with activated forms of the Notch receptors that are produced in the cytoplasm and thus not membrane-localized.

aPKC increases production of NICD, enhances Notch signaling and relocates Notch1 from endosomes to the nucleus

We then tested whether PKC $\zeta$ affected Notch signaling output. Notch signaling was activated in 293 HEK cells stably expressing the full-length Notch1 (293FLN1) by culturing the cells on immobilized Jagged1 ligand, and the downstream signaling was measured by a reporter construct with multimerized CSL-binding sites linked to the luciferase gene $(12 \times$ CSL-luc) [45]. $12 \times$ CSL-luc reporter activity was enhanced by culturing the 293FLN1 cells on immobilized Fc-Jagged 1 as compared to FcIgG as control, and transfection of a constitutively active form of $\mathrm{PKC} \zeta$ ( $\mathrm{caPKC} \zeta$ ) led to a further increase in reporter activity (Figure 3A). Reporter activity resulting from transfection of Notch $1 \Delta \mathrm{E}$ was similarly enhanced by caPKC $\zeta$ (Figure 3B). In contrast, when NICD was transduced, there was no further activation in the presence of caPKC $\zeta$ (Figure 3C), in keeping with the ob- 
A

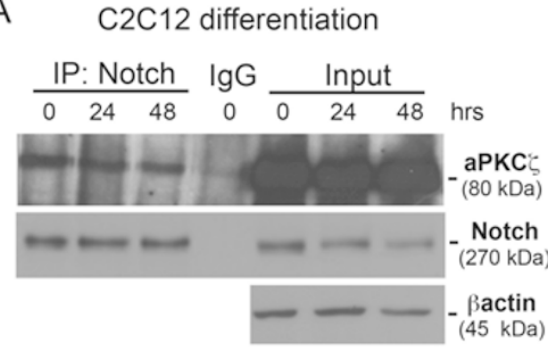

B

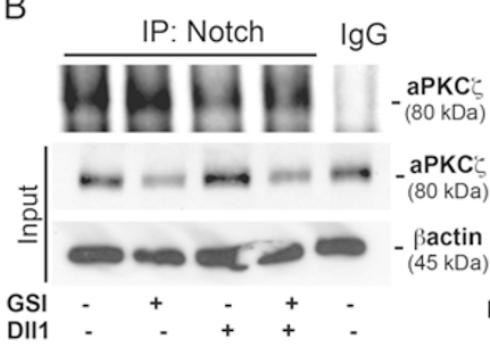

C

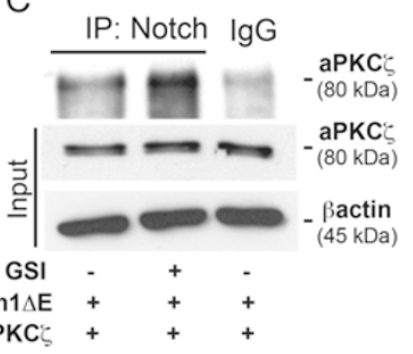

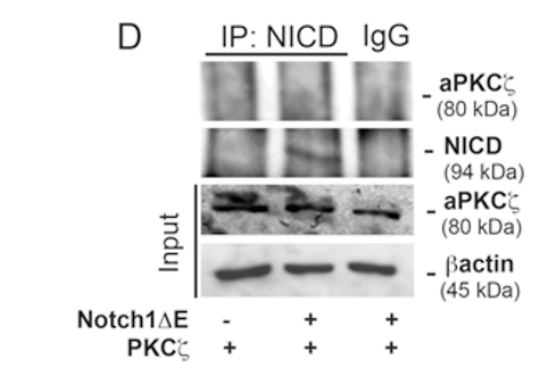

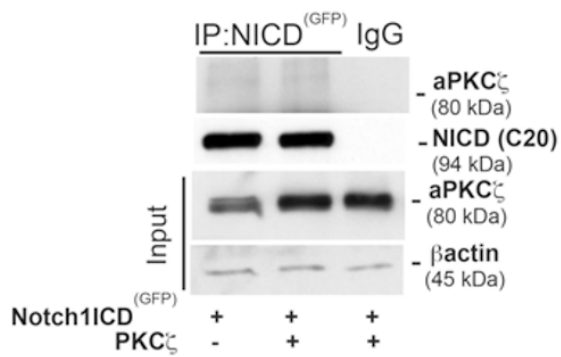

E
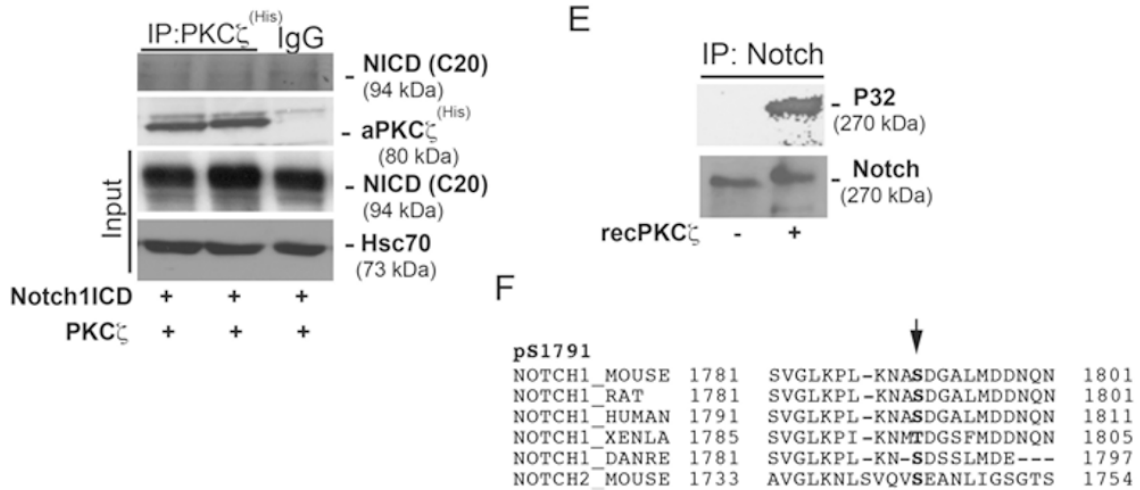

Figure 2 Notch1 interacts with PKC $\zeta$ at the membrane. (A) Untransfected C2C12 cells undergoing differentiation were harvested at different time points and subjected to immunoprecipitation (IP) using a Notch1 antibody (C20 goat). Immunoblotting was performed with an antibody against PKC . (B) Immunoprecipitation of Notch1 from C2C12 cells stably expressing the full-length Notch1 receptor and transfected with constitutively active PKC $\zeta$ (caPKC $\zeta$ ) and grown on immobilized DII1 or Fc-lgG as control. The cells were treated with the $\gamma$-secretase inhibitor (GSI) DAPT for $24 \mathrm{~h}$ prior to harvesting. Immunoblotting was performed with an antibody against PKC $\zeta$. (C) Immunoprecipitation of Notch1 (C20 goat) from HeLa cells transfected with Notch $1 \triangle \mathrm{E}$ and $\mathrm{caPKC} \zeta$ and treated with DAPT or vehicle control for $24 \mathrm{~h}$. Immunoblotting was performed with an antibody against PKC $\zeta$. (D) Left: Immunoprecipitation of NICD (using cleaved-Notch antibody) from 293 HEK cells transfected with Notch $1 \triangle \mathrm{E}$ and $\mathrm{caPKC} \zeta$. Immunoblotting was performed using an antibody against PKC $\zeta$. Right: Immunoprecipitation of PKC $\zeta$ using an antibody against the His tag of PKC $\zeta$ from 293 HEK cells transfected with NICD and PKC . Immunoblotting was performed using an antibody against Notch1 (C20 goat). Below: Immunoprecipitation of Notch1 ICD using a GFP antibody from 293 HEK cells transfected with a GFP-tagged NICD $\left(\mathrm{NICD}^{(\mathrm{GFP})}\right)$ and $\mathrm{caPKC} \zeta$. Immunoblotting was performed using an

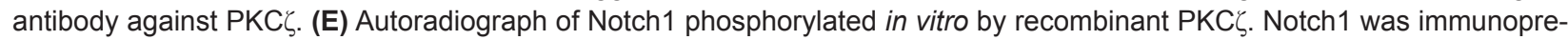
cipitated (C20 goat) from $\mathrm{C} 2 \mathrm{C} 12$ cells. Recombinant $\mathrm{PKC} \zeta$ and ${ }^{32} \mathrm{P}$ ATP were added to the immunoprecipitate. The reaction was incubated at $37{ }^{\circ} \mathrm{C}$ for $15 \mathrm{~min}$ and stopped by adding Laemmli Sample Buffer and boiling for 5 min. The samples were separated by SDS-PAGE and the proteins were transferred to a nitrocellulose membrane. The upper image shows an autoradiograph of the membrane and the lower image shows an immunoblot of the same membrane performed after the radioactive signal had decayed. (F) Sequence alignment shows that the phosphorylation site S1791 is highly conserved in different species and is also present in Notch2.

served lack of interaction between $\mathrm{PKC} \zeta$ and NICD (Figure 2D). Further, caPKC $\zeta$ did not enhance the reporter activity induced by Notch $1 \Delta \mathrm{E}$ carrying a mutation in $\mathrm{K} 1749$ (Notch1 $\Delta \mathrm{E}^{\mathrm{K} 1749 \mathrm{R}}$ ) (Figure 3D). K1749 has been suggested to be critical for monoubiquitylation and subsequent S3-processing of Notch1 $\Delta \mathrm{E}[4]$. An alternative view is that the S3-cleavage site is altered, which generates a short-lived NICD. Our results are compatible with both models.

Co-transfection of Notch $1 \Delta \mathrm{E}$ with $\mathrm{caPKC} \zeta$ or $\mathrm{caPKCl}$ led to increased levels of NICD in a dose-dependent manner (Figure 3E), indicating that caPKCs trigger an 
increased production of NICD from Notch $1 \Delta \mathrm{E}$. To verify whether the observed increase in NICD levels requires aPKC $\zeta$ kinase activity, we used two dominant-negative mutants of the kinases ( $\mathrm{dnPKC} \zeta$ and $\mathrm{dnPKCl})$. The dominant-negative mutants did not enhance Notch processing, demonstrating that kinase activity is required (Figure $3 \mathrm{~F})$. The $\mathrm{caPKC} \zeta /$-induced increase in NICD production was blocked by GSI, suggesting that aPKC $\zeta / \iota$ operate upstream of S3 cleavage (Figure 3F).

The observation that inhibition of $\mathrm{PKC} \zeta$ shifted the localization of Notch $1 \Delta \mathrm{E}$ towards the cytoplasm in vivo (Figure 1 and Supplementary information, Figure $\mathrm{S} 1)$ suggests that $\mathrm{caPKC} \zeta / \mathrm{l}$-enhanced $\mathrm{S} 3$ cleavage and Notch activation may occur in endosomes. In keeping with this, blocking dynamin-induced internalization of the Notch receptor by dynasore [46] in cells expressing $\mathrm{caPKC} \zeta$ resulted in reduced amounts of NICD following ligand-induction (Figure 3G). To further extend these observations, we investigated the possible role of aPKC in intracellular Notch localization. In 293 HEK cells, Notch 1 was predominantly localized in intracellular vesicles and only to a smaller extent in the nucleus (Figure $3 \mathrm{H})$. Co-expression of Notch $1 \Delta \mathrm{E}$ with $\mathrm{caPKC} \zeta$ shifted the Notch immunoreactivity to the nucleus, whereas expression of $\mathrm{dnPKC} \zeta$ resulted in Notch immunoreactivity predominantly in vesicles in the cytoplasm (Figure 3H). A similar shift in intracellular localization was observed in $\mathrm{C} 2 \mathrm{C} 12$ cells, in which dnPKC $\zeta$ enhanced the presence of Notch immunoreactivity in cytoplasmic vesicles, at the expense of nuclear localization (Figure 3I, left). Expression of caPKC $\zeta$, but not $\mathrm{dnPKC} \zeta$, resulted in an increase in NICD expression as demonstrated by western blotting (Figure 3I, right). The localization of Notch1 in the nucleus in $\mathrm{PKC}$-expressing cells was shifted to cytoplasmic vesicles upon GSI treatment, suggesting that PKC $\zeta$ operates upstream of endosomal S3 cleavage and nuclear translocation (Supplementary information, Figure S5). Together, these data suggest that under conditions of active Notch signaling, aPKC further enhances Notch signaling by increasing production of NICD from Notch $1 \Delta \mathrm{E}$ and shifting the localization of Notch1 from intracellular vesicles to the nucleus, which corroborates the in vivo observations.

Numb is a negative regulator of Notch signaling [47] and regulates Notch endocytosis [48]. Numb has recently been shown to be phosphorylated by aPKCs [49], which prompted us to test whether the effect of PKC $\zeta$ on Notch was influenced by Numb. Overexpression of Numb reduced Notch activity (Supplementary information, Figure S2), in keeping with previous reports [48]. Importantly, Numb overexpression did override the enhancing effect of PKC $\zeta$ as expression of Numb together with $\mathrm{caPKC} \zeta$ reduced signaling from Notch $1 \Delta \mathrm{E}$ (Supplemen- tary information, Figure S6). Furthermore, expression of Numb combined with blocking of $\mathrm{PKC} \zeta$ led to a stronger inhibition of Notch activity as compared to expression of Numb or blocking of PKC $\zeta$ alone (Supplementary information, Figure S6). These data suggest that Numb and $\mathrm{PKC} \zeta$ affect Notch signaling at distinct steps.

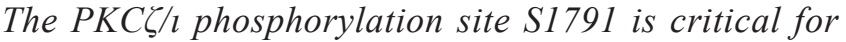
NICD production, Notch intracellular localization and Notch signaling

To assess the effect of $\mathrm{PKC} / \mathrm{l}$-mediated phosphorylation of Notch1 at S1791 (Figure 2 and Supplementary information, Figure S3), we generated $\mathrm{PKC}$ / 1-phosphorylation-deficient and phosphomimetic forms of Notch1 $\Delta \mathrm{E}$ : Notch $1 \Delta \mathrm{E}^{\mathrm{S} 1791 \mathrm{~A}}$ and Notch $1 \Delta \mathrm{E}^{\mathrm{S} 1791 \mathrm{E}}$, respectively. In addition, we generated a phosphomimetic form of the full-length receptor Notch1FLN ${ }^{\mathrm{S} 1791 \mathrm{E}}$ (Figure 4A). Treatment with GSI, which blocks S3 cleavage, revealed that although similar amounts of uncleaved Notch $1 \Delta \mathrm{E}$ protein were produced from Notch $1 \Delta \mathrm{E}$ and Notch $1 \Delta \mathrm{E}^{\mathrm{S} 1791 \mathrm{~A}}$ (Figure 4B, upper), expression of Notch $1 \Delta \mathrm{E}^{\mathrm{S} 1791 \mathrm{~A}}$ led to a significant decrease in the level of NICD in 293 HEK cells (Figure 4B, lower). Consistently, $12 \times$ CSL-luc activity in response to Notch $1 \Delta \mathrm{E}^{\mathrm{S} 1791 \mathrm{~A}}$ expression was decreased compared with Notch $1 \Delta \mathrm{E}$ expression (Figure 4C). Conversely, expression of the phosphomimetic mutant Notch $1 \Delta \mathrm{E}^{\mathrm{S} 1791 \mathrm{E}}$ resulted in an enhanced production of NICD (Figure 4B, lower) and $12 \times$ CSL-luc reporter activity (Figure $4 \mathrm{C}$ ) compared with Notch $1 \Delta \mathrm{E}$ expression. Interestingly, when caPKC $\zeta$ was co-expressed with Notch $1 \Delta \mathrm{E}, 12 \times \mathrm{CSL}$-luc reporter activity was further increased, whereas caPKC $\zeta$ did not enhance the reporter activity from Notch $1 \Delta \mathrm{E}^{\mathrm{S} 1791 \mathrm{~A}}$ (Figure 4D). On the contrary, the reporter activity was reduced which might reflect downregulation of endogenous Notch activity. Both Dll1 (Figure 4E) and Jagged1 (data not shown) induced an enhanced activation of the phosphomimetic form of the full-length receptor Notch1FLN $^{\mathrm{S} 1791 \mathrm{E}}$ (Figure 4E) and higher levels of NICD were detected (Supplementary information, Figure S7) as compared to wild-type full-length Notch1. This effect was dose-dependent, i.e., more pronounced at high concentrations of ligands (Figure 4F).

To assess whether the increased level of NICD following $\mathrm{caPKC} \zeta$ expression was due to altered stability of NICD, we performed a cycloheximide (CHX) chase experiment. Expression of $\mathrm{caPKC} \zeta$ did not affect the decrease rate of NICDs produced from the various Notch $1 \Delta \mathrm{E}$ forms (Supplementary information, Figure S8A). Treatment with the proteasome inhibitor MG132 yielded no significant difference in the degradation rate of the NICDs generated from different mutants (Supplementary information, Figure S8B). Further, caPKC $\zeta$ 

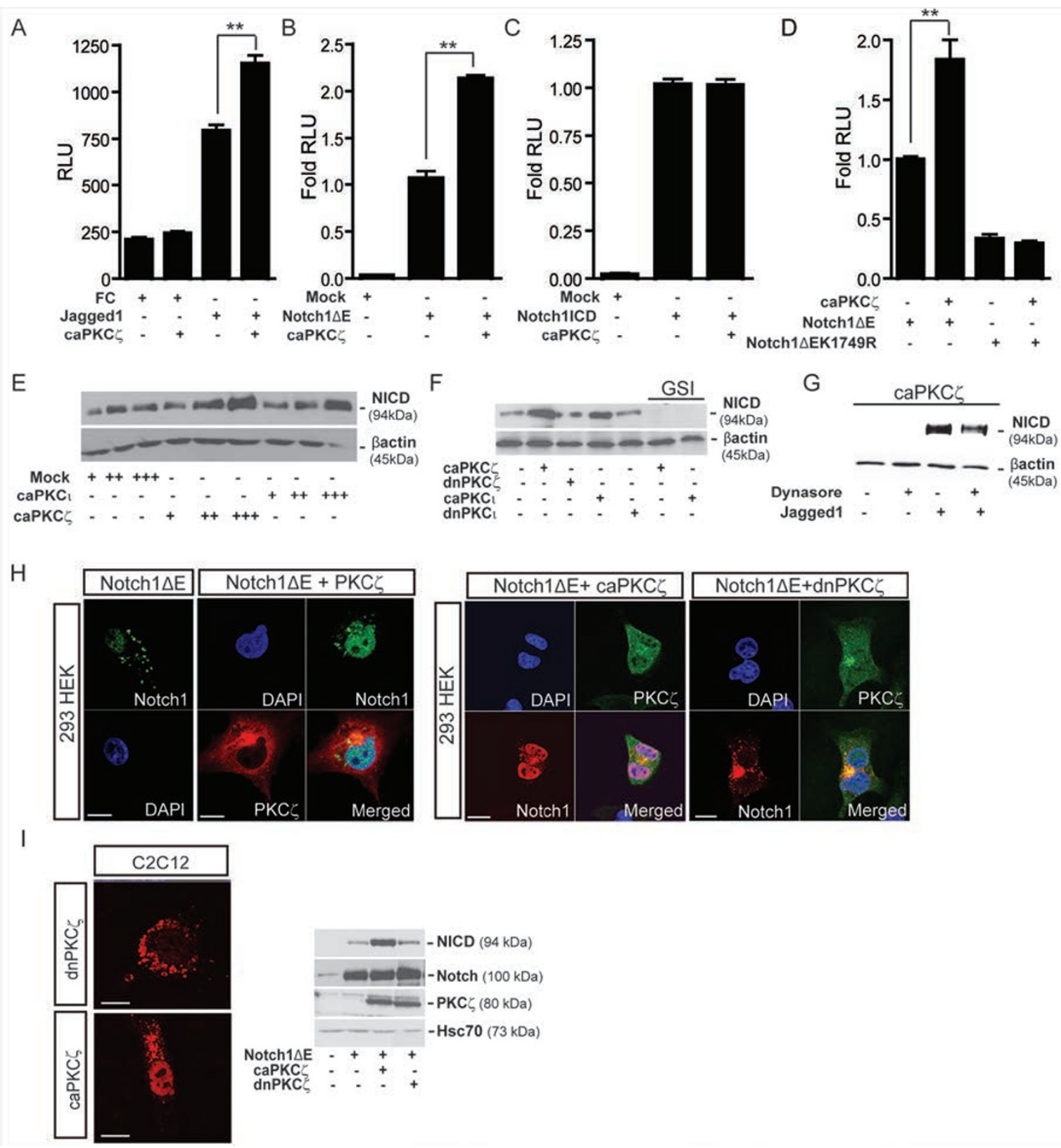

Figure 3 PKC $\zeta$ increases NICD levels and enhances Notch signaling. (A) Notch signaling activity was measured using a luciferase-based reporter system (12×CSL-luc). 293 HEK cells stably expressing full-length Notch1 (293FLN1) were transfected with $12 \times$ CSL-luc, CMV- $\beta$-galactosidase and $\mathrm{caPKC} \zeta$ or empty vector and grown on immobilized recombinant Jagged 1 or Fc-IgG (FC) control. (B-D) The luciferase-based reporter system was used to measure the signaling activity of Notch1 $\Delta \mathrm{E}$ and NICD in the presence and absence of caPKC $\zeta .293$ HEK cells were transfected with $12 \times C S L-l u c$, CMV- $\beta$-galactosidase, Notch1 $\triangle \mathrm{E}(\mathrm{B}), \mathrm{NICD}$ (C) or the monoubiquitylation mutant Notch1 $\triangle \mathrm{EK} 1749 \mathrm{R}$ (D) and caPKC $\zeta$ or empty vector. The figures in A-D represent means from three separate experiments. Error bars indicate SD. (E) Western blot analysis using a cleavedNotch antibody against NICD in 293 HEK cells transfected with Notch1 $1 \mathrm{E}$ and increasing amounts of caPKC $\zeta$, caPKCi or empty vector. (F) Western blot using a cleaved-Notch antibody in $293 \mathrm{HEK}$ cells transfected with Notch1 $\triangle \mathrm{E}$ and caPKC $\zeta$, dnPKC $\zeta$, caPKC 1 or dnPKCl. The cells were treated with GSI DAPT for $24 \mathrm{~h}$ prior to harvesting. (G) Western blot using a cleaved-Notch antibody on caPKC $\zeta$-transfected 293FLN1 cells grown on immobilized Jagged1 in the presence or absence of the dynamin inhibitor Dynasore $(80 \mu \mathrm{M}, 2 \mathrm{~h})$. (H) $293 \mathrm{HEK}$ cells transfected with Notch1 $\Delta \mathrm{E}$ and $\operatorname{caPKC} \zeta$ or dnPKC $\zeta$ were stained with antibodies against Notch 1 and $\mathrm{PKC} \zeta$ and counterstained with DAPI. (I) Representative microscopy images showing localization of Notch1 in $\mathrm{C} 2 \mathrm{C} 12$ cells transfected with caPKC $\zeta$ or dnPKC $\zeta$ and Notch1 $\triangle \mathrm{E}$. The western blot shows expression of NICD, Notch1 and PKC $\zeta$ in $\mathrm{C} 2 \mathrm{C} 12$ cells transfected with Notch1 $\triangle \mathrm{E}$ and caPKC $\zeta$ or dnPKC . Heat shock protein 70 (Hsc70) was used as a loading control. Scale bars in $\mathbf{H}$ and $\mathbf{I}, 10 \mu \mathrm{m}$. 
A

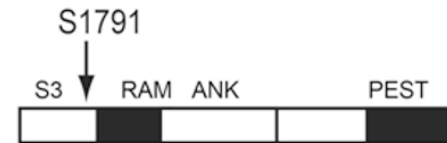

Notch1 $1 \triangle$ E SVGLKPLKNASDGALMDDNQN Notch1 1 ES1791A SVGLKPLKNAADGALMDDNQN Notch1 1 ES1791E SVGLKPLKNAEDGALMDDNQN Notch1FLN SVGLKPLKNASDGALMDDNQN Notch1FLNS1791E SVGLKPLKNAEDGALMDDNQN
B

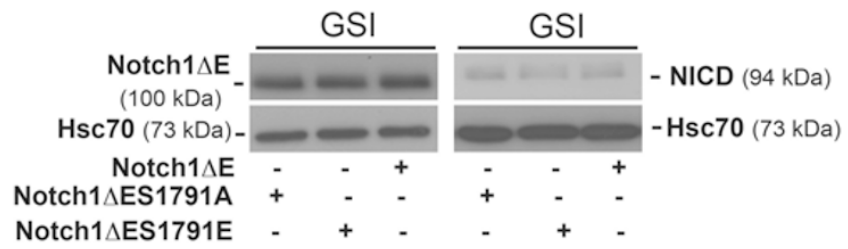

Control

C

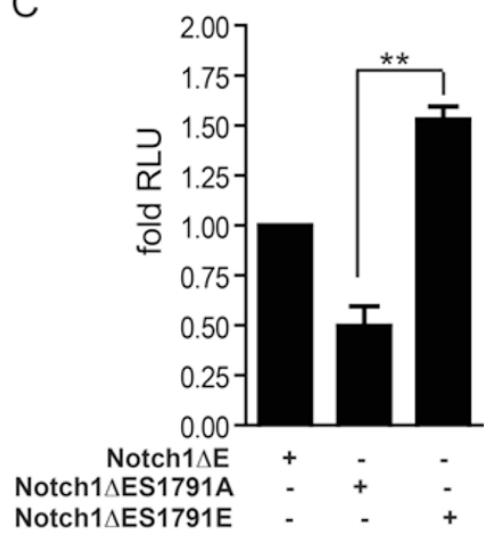

D

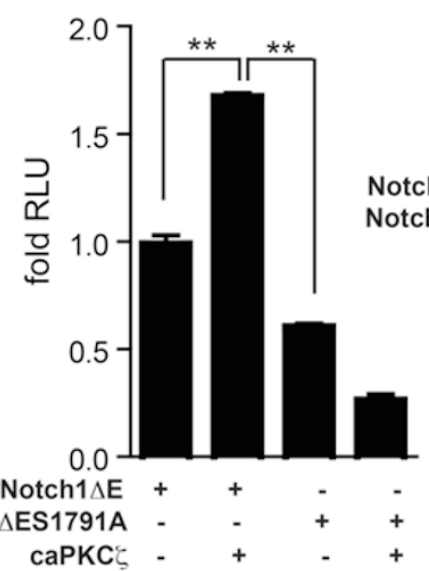

E

Notch1 $\triangle \mathrm{ES} 1791 \mathrm{~A}$ CaPKC $C$

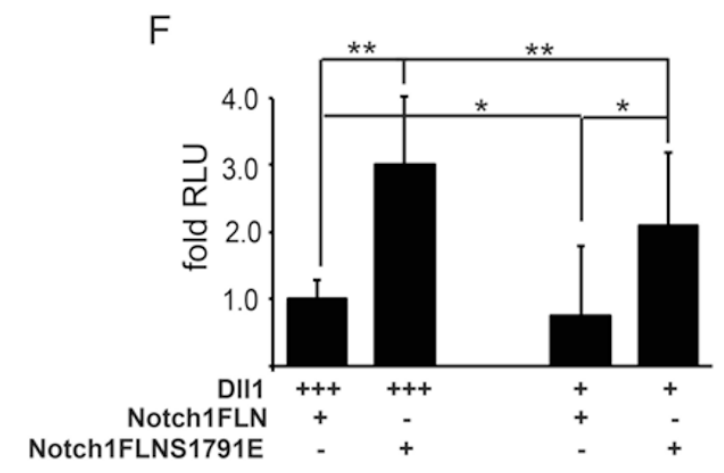

Figure 4 Phosphorylation at S1791 enhances Notch signaling. (A) Schematic depiction of the wild-type and mutant Notch1 $\Delta \mathrm{E}$ and the full-length Notch1 (Notch1FLN). (B) Western blot with antibodies against Notch1 to detect Notch1 $\Delta E$ and NICD in $293 \mathrm{HEK}$ cells transfected with Notch $1 \Delta \mathrm{E}$, Notch $1 \Delta \mathrm{E}^{\mathrm{S} 1791 \mathrm{~A}}$ or Notch $1 \Delta \mathrm{E}^{\mathrm{S} 1769 \mathrm{E}}$. The cells were treated with the $\gamma$-secretase inhibitor (GSI) or vehicle control (Control) for 24 h. (C) Notch signaling activity was measured using a luciferase-based reporter

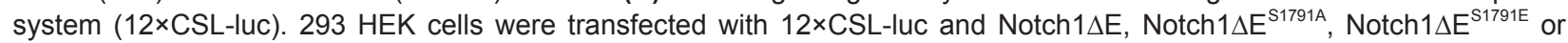
empty vector. (D) Notch signaling activity in cells co-transfected with caPKC $\zeta$ and Notch $1 \Delta \mathrm{E}$ or Notch $1 \Delta \mathrm{E}^{\mathrm{S} 1791 \mathrm{~A}}$. (E) Notch signaling activity in cells transfected with Notch1FLN or Notch1FLN ${ }^{\text {S1791E }}$ and activated by immobilized DII1 ligands. (F) Notch signaling activity in cells transfected with Notch1FLN or Notch1FLN ${ }^{\text {S1791E }}$ and activated by various concentrations of immobilized DII1 ligands. For the lower concentration, the conditioned medium containing DII1 was diluted 1/3 before immobilization of ligand. Data represent a mean from three separate experiments. Error bar indicates SD and statistical significance is denoted as ${ }^{* *} P<0.01,{ }^{*} P<0.05$.

did not significantly affect the stability of NICD in cells transfected with caPKC $\zeta$ and NICD (Supplementary information, Figure S8C). Taken together, these data suggest that NICD stability is not altered by aPKC $\zeta$.

Upon blocking of lysosomal function, the levels of Notch $1 \Delta \mathrm{E}^{\mathrm{S} 1791 \mathrm{~A}}$ increased significantly, whereas the levels of Notch $1 \Delta \mathrm{E}$ only increased slightly and the levels of
Notch1 $\Delta \mathrm{E}^{\mathrm{S} 1791 \mathrm{E}}$ showed no change (Supplementary information, Figure S8E). Blocking of lysosomal degradation during a CHX chase inhibited the reduction in the level of Notch $1 \Delta \mathrm{E}^{\mathrm{S} 1791 \mathrm{~A}}$ but not that of Notch1 $\Delta \mathrm{E}$ (Supplementary information, Figure S8F). This is in line with the data that the interaction between Notch1 and lysosomal protein LAMP1 was enhanced and Notch1 accumulated 
in lysosomes upon $\mathrm{PKC}$ inhibition (Figure 5G-5H). These observations also support the notion that NEXT is contained in endocytic vesicles, routed to lysosomes and degraded when $\mathrm{PKC} \zeta$ is inactivated. Furthermore, the observation that aPKC $\zeta$ does not directly alter the stability of NICD but that inhibition of aPKC $\zeta$ leads to lysosomal routing and degradation of Notch is in keeping with the in vivo observations that Notch 1 accumulated in vesicles and the number of Notch1-expressing cells went down upon $\mathrm{APKC} \zeta$ inhibition (Figure 1).

We next assessed the intracellular localization of the different Notch $1 \Delta \mathrm{E}$ forms. Notch $1 \Delta \mathrm{E}$ and $\operatorname{Notch} 1 \Delta \mathrm{E}^{\mathrm{S} 1791 \mathrm{E}}$ showed pronounced nuclear localization with limited immunolabeling of intracellular vesicles (Figure 5A). In contrast, Notch $1 \Delta \mathrm{E}^{\mathrm{S} 1791 \mathrm{~A}}$ was localized predominantly in cytoplasmic vesicles with very limited nuclear localization (Figure 5A), which resembles the distribution pattern of Notch1 in cells co-expressing Notch1 $\Delta \mathrm{E}$ and dnPKC $\zeta$ (Figure $3 \mathrm{H}$ ) or in the chick CNS upon pharmacological inhibition of $\mathrm{PKC} \zeta$. Consistently, the amount of NICD protein in the nucleus was indeed increased when the phosphomimetic mutant Notch $1 \Delta \mathrm{E}^{\mathrm{S} 1791 \mathrm{E}}$, not Notch $1 \Delta \mathrm{E}^{\mathrm{S} 1791 \mathrm{~A}}$, was expressed compared with wild-type Notch $1 \Delta \mathrm{E}$ overexpression (Figure $5 \mathrm{~B}$ ). The purity of the nuclear fraction was demonstrated by the absence of markers for Golgi and endoplasmic reticulum (Supplementary information, Figure S9). A similar increase in the percentage of cells with activated nuclear Notch1 was observed for Notch $1 \Delta \mathrm{E}^{\mathrm{S} 1791 \mathrm{E}}$ (Figure 5C).

To explore which type of intracellular vesicles Notch1 was localized to, we analyzed whether the phosphomimetic and phosphodeficient forms of Notch $1 \Delta \mathrm{E}$ interacted with the endosomal proteins Rab5, Rab7 and Lamp1. Rab5 is a marker for early endsosomes, while Rab7 and Lamp1 are associated with late endosomes and late endosomal/lysosomal compartment, respectively [50]. Both phosphomimetic and phosphodeficient forms of Notch $1 \Delta \mathrm{E}$ were present in Rab5- and Rab7-positive vesicles (Figure 5D). Further, all three Notch $1 \Delta \mathrm{E}$ forms interacted with both Rab5 and Rab7, although Notch $1 \Delta \mathrm{E}^{\mathrm{S} 1791 \mathrm{E}}$ showed a somewhat reduced interaction with Rab7 (Figure 5E). Notch1 $\Delta \mathrm{E}^{\mathrm{S} 1791 \mathrm{~A}}$ showed enhanced interaction with Lamp1, as compared to Notch $1 \Delta \mathrm{E}$ (Figure $5 \mathrm{~F}$ ). Knockdown of $\mathrm{PKC} \zeta$ mRNA expression by siRNA enhanced the interaction between endogenous Notch1 and Lamp1 in C2C12 cells (Figure 5G). Similarly, pharmacological inhibition of $\mathrm{PKC} \zeta$ for $24 \mathrm{~h}$ led to accumulation of Notch1 immunoreactivity in Lamp1positive late endosomes/lysosomes but not in EEA1positive early endosomes (Figure 5H). This is in line with the data showing enhanced lysosomal degradation of phosphodeficient forms of Notch1 (Supplementary information, Figure S8). Taken together, these data indicate that $\mathrm{PKC} \zeta$-mediated phosphorylation of Notch1 promotes its processing in late endosomes/lysosomes and thereby enhances nuclear translocation of Notch1, and conversely, blocking of PKC $\zeta$ results in Notch1 accumulation in Lamp1-positive late endosomes/lysosomes, eventually leading to degradation of the ligand-activated Notch1.

An aPKC $\zeta$ phosphorylation-deficient Notch $1 \Delta E$ mutant does not block myogenic differentiation

Notch keeps myogenic progenitors in an undifferentiated state and blocks differentiation to myotubes [45, $51,52]$. We next tested whether the phosphorylation of Notch1 at S1791 by aPKC $\zeta$ was important for Notch1 control of myogenic differentiation. When aPKC $\zeta$ was pharmacologically inhibited in primary myoblasts or $\mathrm{C} 2 \mathrm{C} 12$ cells (data not shown), a reduction in the amount of NICD was observed (Figure 6A). Pharmacological inhibition of $\mathrm{aPKC} \zeta$ also resulted in a pronounced increase in the number of cells expressing the differentiation marker myosin heavy chain (MHC) $48 \mathrm{~h}$ after induction of differentiation in primary myoblasts (Figure 6B). Further, downregulation of $\mathrm{PKC} \zeta$ in $\mathrm{C} 2 \mathrm{C} 12$ myoblasts reduced Notch activity and caused a precocious upregulation of MHC levels (Figure 6C). Conversely, when C2C12 myoblast cells were shifted to differentiationpromoting conditions, overexpression of $\mathrm{caPKC} \zeta$ or caPKCr resulted in increased NICD levels (Figure 6D and Supplementary information, Figure S10). An increase in the proportion of $\mathrm{C} 2 \mathrm{C} 12$ cells expressing $\mathrm{MHC}$ was observed after Notch $1 \Delta \mathrm{E}^{\mathrm{S} 1791 \mathrm{~A}}$ expression: $29 \%$ of Notch $1 \Delta \mathrm{E}^{\mathrm{S} 1791 \mathrm{~A}}$-expressing cells were MHC-positive, while only $10 \%$ of Notch $1 \Delta \mathrm{E}$-expressing cells expressed $\mathrm{MHC}$ at $48 \mathrm{~h}$ of differentiation (Figure $6 \mathrm{E}$ ). At $72 \mathrm{~h}$, there were $71 \% \mathrm{MHC}$-positive cells for Notch $1 \Delta \mathrm{E}^{\mathrm{S} 1791 \mathrm{~A}}$ as compared to $14 \%$ for Notch $1 \Delta \mathrm{E}$ expression (Figure $6 \mathrm{E})$. In conclusion, these data show that $\mathrm{aPKC} \zeta$ activity influences myogenic differentiation, and that the phosphorylation-deficient Notch $1 \Delta \mathrm{E}$ mutant is unable to block myogenic differentiation.

PKCS promotes a shift in Notch receptor distribution from the cell surface to endosomes in the non-activated state

The data above demonstrate that under conditions of activated Notch signaling, either by ligand stimulation or expression of Notch $1 \triangle \mathrm{E}, \mathrm{PKC} \zeta$ augments the Notch signaling response. As $\mathrm{PKC} \zeta$ interacted with the fulllength Notch1 that was not ligand-activated (Figure 2), it is possible that PKC may also exert an effect on Notch1 in the non-activated state. We therefore tested whether 
A
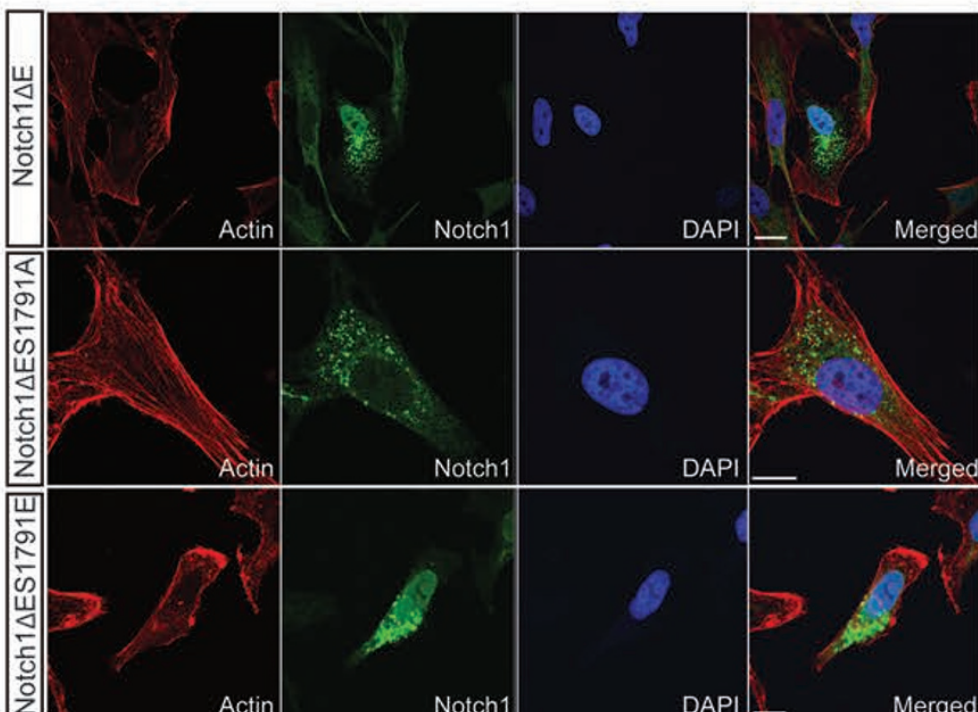

Notch1

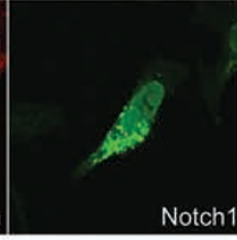

D

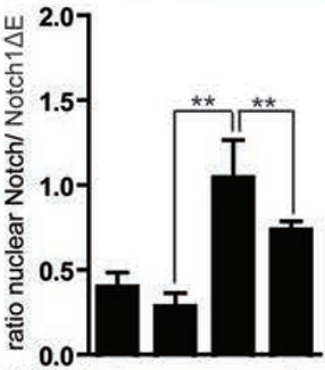

Notch1 $\triangle E+-\quad+$

Notch1 $\triangle$ ES1791A - + -

Notch1 $\triangle E S 17$

caPKC

E

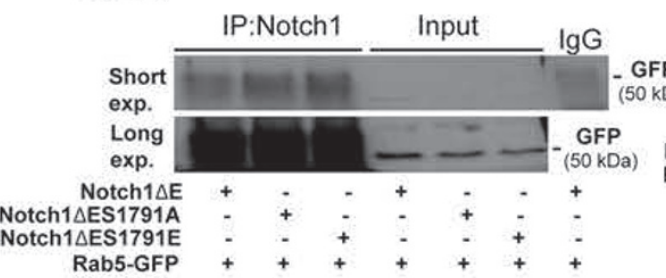

F

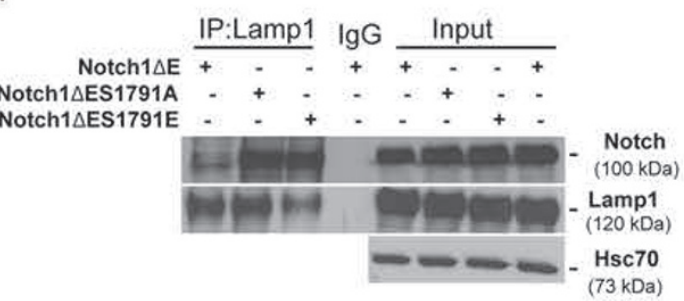

G

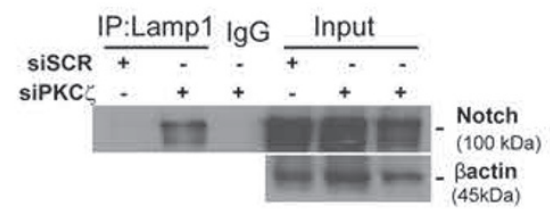

C

kDa)

Notch1 $\triangle$ ES1791A

Notch1 $\triangle E S 1791 E$

Rab7-GFP

$\mathrm{H}$
DAPI

Merged

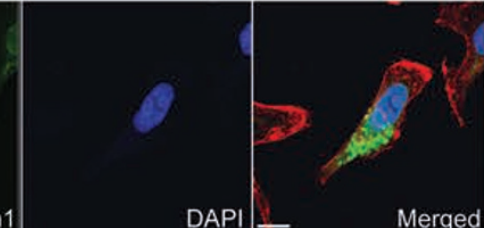

B
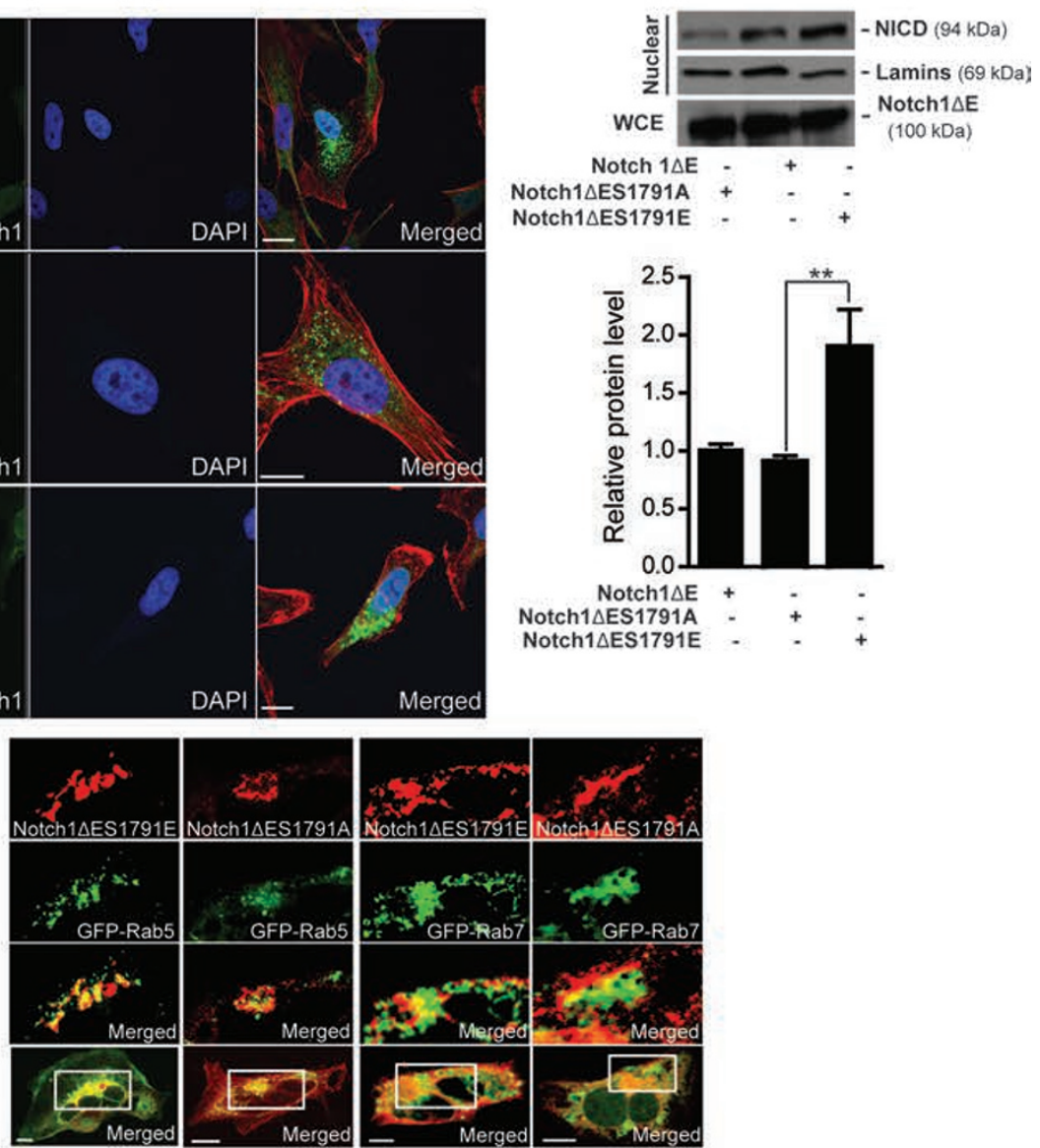

Notch1 $\triangle E S 1791 A$

Notch1 $\triangle E S 1791 E$
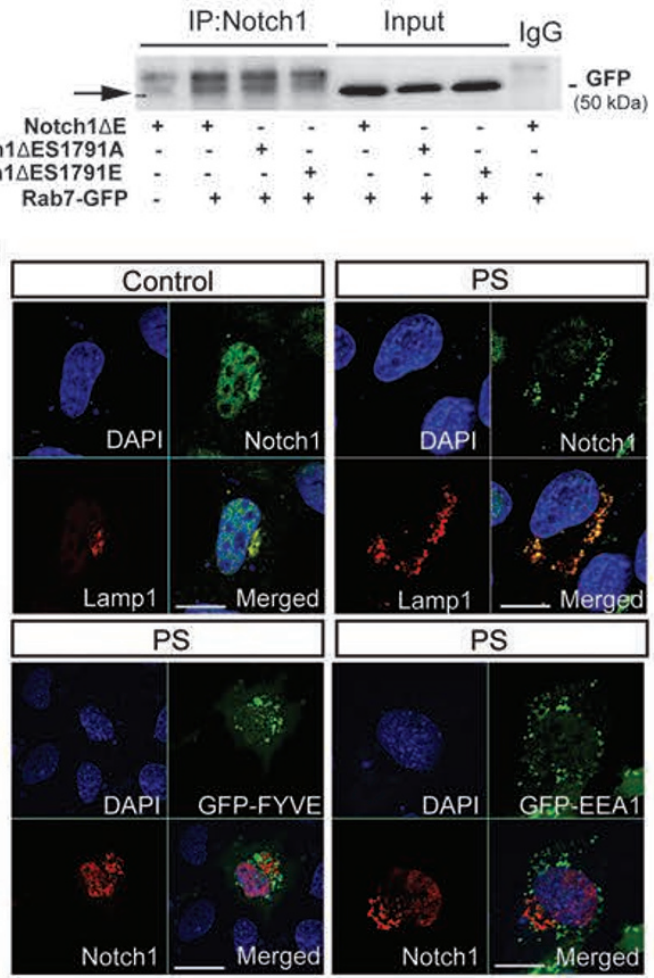
PKC $\zeta$ affected full-length Notch1 distribution in the nonactivated state, i.e., when cells were cultured very sparsely and did not contact each other, thus avoiding cell-cell interaction and activation of Notch. Under these conditions, expression of caPKC $\zeta$ in 293 HEK cells (293FLN1 cells) or in $\mathrm{C} 2 \mathrm{C} 12$ cells, both stably expressing fulllength Notch1, resulted in a shift of Notch1 distribution from the cell surface to intracellular vesicles (Figure 7A and 7B). To further assess receptor internalization, we labeled Notch1 on the cell surface with a fluorescently tagged antibody at $4{ }^{\circ} \mathrm{C}$. After transfer to $37{ }^{\circ} \mathrm{C}$, the internalization of Notch1 was determined by flow cytometry, and cells transfected with $\mathrm{caPKC} \zeta$ showed higher internalization of Notch1 than control cells (Figure 7C).

The low level of NICD observed in sparsely cultured $\mathrm{C} 2 \mathrm{C} 12$ cells as well as the low $12 \times \mathrm{CSL}$-luc basal activity were further reduced by caPKC $\zeta$ (Figure 7D). Receptor ubiquitylation is an important event in receptor internalization and degradation, and we tested whether aPKC-mediated Notch1 internalization was accompanied by Notch1 ubiquitylation. Overexpression of both aPKC1 and aPKC $\zeta$ in sparsely cultured $\mathrm{C} 2 \mathrm{C} 12$ cells led to increased ubiquitylation of Notch1 when lysosomal maturation or endosomal trafficking was blocked by chloroquine (Figure 7E). As an alternative measure of receptor internalization, we explored whether Notch1 interacted with Hrs, which is an endosome-associated ubiquitinbinding protein involved in cargo selection and important for endosomal sorting. Transfection of $\mathrm{caPKC} \zeta$ resulted in an enhanced interaction between Notch1 and Hrs in the non-activated state (Figure 7F). Although aPKC enhanced internalization of Notch1, this was not associated with increased lysosomal degradation, as chloroquine treatment resulted in a similar increase in Notch1 protein levels in the absence and presence of PKCל (Figure $7 \mathrm{G})$. Unexpectedly, in a cell surface protein biotinylation experiment, we did not observe a decrease in Notch1 at the surface of cells expressing PKC $\zeta$ (Figure 7H). While these data indicate that a full-length Notch receptor not engaged in Notch signaling could be internalized to endosomes, we attempted to extend the analysis to address whether a full-length receptor that never even reaches the cell surface could be relocalized to endosomes by aPKC. To this end, we engineered a full-length Notch1 lacking the two ligand-interacting EGF repeats 10 and 11 (FLN1 $\triangle$ EGF10-11), which was trapped in the ER/ Golgi compartment and therefore unable to engage in activation in trans by ligands (Supplementary information, Figure S11). Co-expression with PKC $\zeta$ resulted in a shift in intracellular localization of Notch1, which was predominantly localized to endosomal vesicles (Supplementary information, Figure S11). This indicates that full-length Notch receptors can be moved from the exocytic pathway to endosomes and that aPKC presumably interacts with Notch receptors early in the process. In conclusion, these data suggest that when Notch1 is in the non-activated state, aPKC $\zeta$ serves to shift the distribution of Notch receptors from the cell surface and the secretory pathway to intracellular vesicles, which is not accompanied by enhanced Notch signaling nor enhanced degradation.

\section{Discussion}

In Notch signaling, receptor internalization is an integral part of the intracellular signaling cascade. However, it is still largely unknown how endocytosis and intracellular routing of the Notch receptor are controlled. In this report, we demonstrate that $\mathrm{PKC} \zeta$ interacts with and phosphorylates Notch1 and acts as a novel regulator of Notch receptor trafficking. $\mathrm{PKC} \zeta$ controls two distinct steps in Notch receptor intracellular routing, depending on the Notch signaling state. During active Notch signaling, i.e., after ligand stimulation or after expression of an activated membrane-tethered form of Notch, PKC $\zeta$ enhances production of NICD and shifts the localization of Notch from late endosomes to the nucleus, leading to elevated Notch signaling. In contrast, when the Notch re-

Figure 5 Phosphorylation at S1791 affects intracellular localization of Notch1. (A) Representative microscopy images showing the localization of Notch $1 \Delta \mathrm{E}$, Notch $1 \Delta \mathrm{E}^{\mathrm{S} 1791 \mathrm{~A}}$ or Notch $1 \Delta \mathrm{E}^{\mathrm{S} 1791 \mathrm{E}}$. (B) Western blot using an antibody against NICD of nuclear extracts isolated from cells transfected with Notch $1 \Delta \mathrm{E}^{\mathrm{S} 1791 \mathrm{~A}}$, Notch $1 \Delta \mathrm{E}^{\mathrm{S} 1791 \mathrm{E}}$ or Notch $1 \Delta \mathrm{E}$. The graph (below) shows the quantification of nuclear levels of NICD from three different experiments. (C) The ratio of cells containing nuclear Notch immunoreactivity to all cells with Notch immunoreactivity (nuclear+cytoplasmic) in cells transfected with Notch $1 \Delta \mathrm{E}, \operatorname{Notch} 1 \Delta \mathrm{E}^{\mathrm{S} 1791 \mathrm{~A}}$ or Notch $1 \Delta \mathrm{E}^{\mathrm{S} 1791 \mathrm{E}}$. (D) Representative microscopy images showing the colocalization of Notch $1 \Delta \mathrm{E}^{\mathrm{S} 1791 \mathrm{~A}}$ or Notch $1 \Delta \mathrm{E}^{\mathrm{S} 1791 \mathrm{E}}$ with Rab5 and Rab7. (E) Immunoprecipitation of Notch1 from 293 HEK cells transfected with either wild-type or mutant Notch1 $\Delta E$ and GFP-Rab5 or GFP-Rab7. Immunoblotting was performed with an antibody against GFP. (F) Immunoprecipitation of Lamp1 from $293 \mathrm{HEK}$ cells transfected with Notch1 $\Delta \mathrm{E}$, Notch1 $\Delta \mathrm{E}^{\mathrm{S} 1791 \mathrm{~A}}$ or Notch1 $\Delta \mathrm{E}^{\mathrm{S} 1791 \mathrm{E}}$. (G) Confluent C2C12 cells treated with siRNA against PKC $\zeta(\mathrm{siPKC} \zeta$ ) or control (siSCr) were lysed and subjected to immunoprecipitation using a Lamp1 antibody. Immunoblotting was performed with an antibody against Notch1 to detect NEXT. (H) Immunofluorescence images showing the localization of Notch1 in $\mathrm{C} 2 \mathrm{C} 12$ cells. The late endosomal/lysosomal marker Lamp1 versus the early/sorting endosomal markers EEA1 and FYVE in cells treated with the PKC $\zeta$ inhibitor (PS). Scale bars, $10 \mu \mathrm{m}$. 
ceptor is not activated, i.e., in cells cultured very sparsely and thus not engaged in cell-cell contact, $\mathrm{PKC} \zeta$ interacts with the receptor to induce a shift in receptor distribution from the plasma membrane to intracellular vesicles, a transition which is not accompanied by enhanced Notch signaling.

We present several lines of evidence supporting the notion that $\mathrm{PKC} \zeta$ under active Notch signaling promotes S3 cleavage of membrane-tethered forms of Notch1 that are localized to late endosomes, which results in libera- tion of NICD and its nuclear entry. First, knockdown of endogenous $\mathrm{PKC} \zeta$ enhanced the interaction of Notch1 with Lamp1, a marker for late endosomes/lysosomes and blocking of PKC $\zeta$ in the CNS in vivo reduced the number of cells with nuclear Notch1. Second, expression of a constitutively active PKC $\zeta$ shifted the Notch1 distribution from endosomes to the nucleus. In keeping with this, elevated $\mathrm{PKC} \zeta$ activity resulted in increased Notch signaling output, indicative of increased presence of NICD in the nucleus. Third, the identification of S1791
A

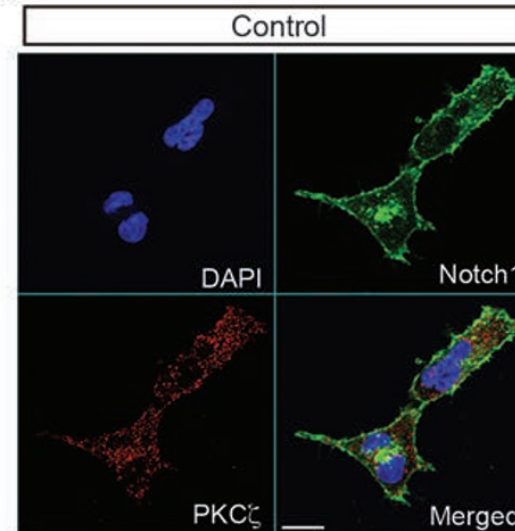

B

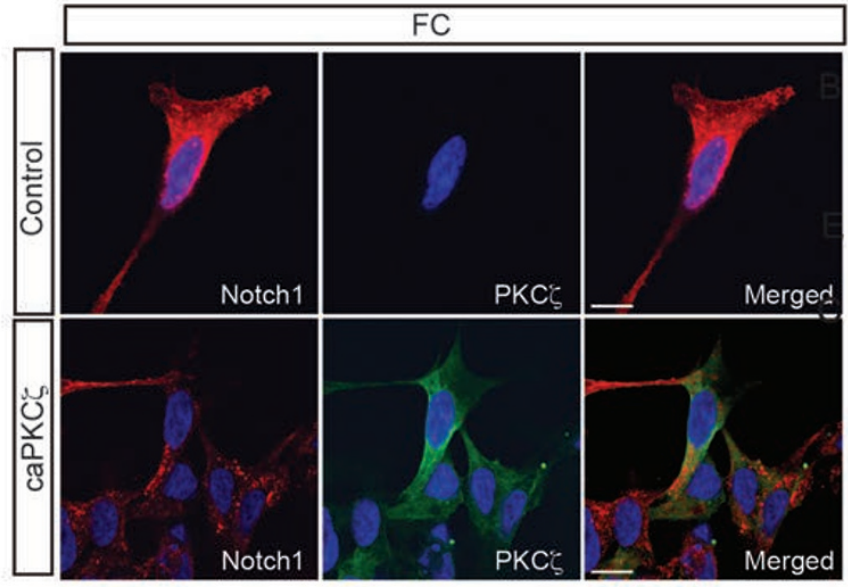

E

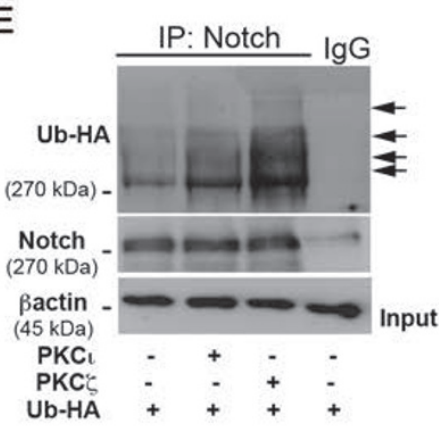

F
C

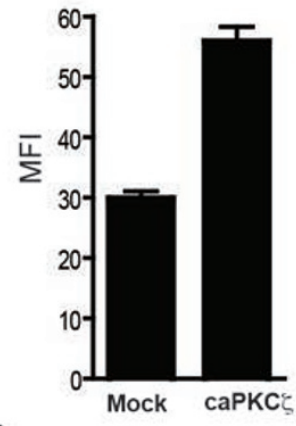

D
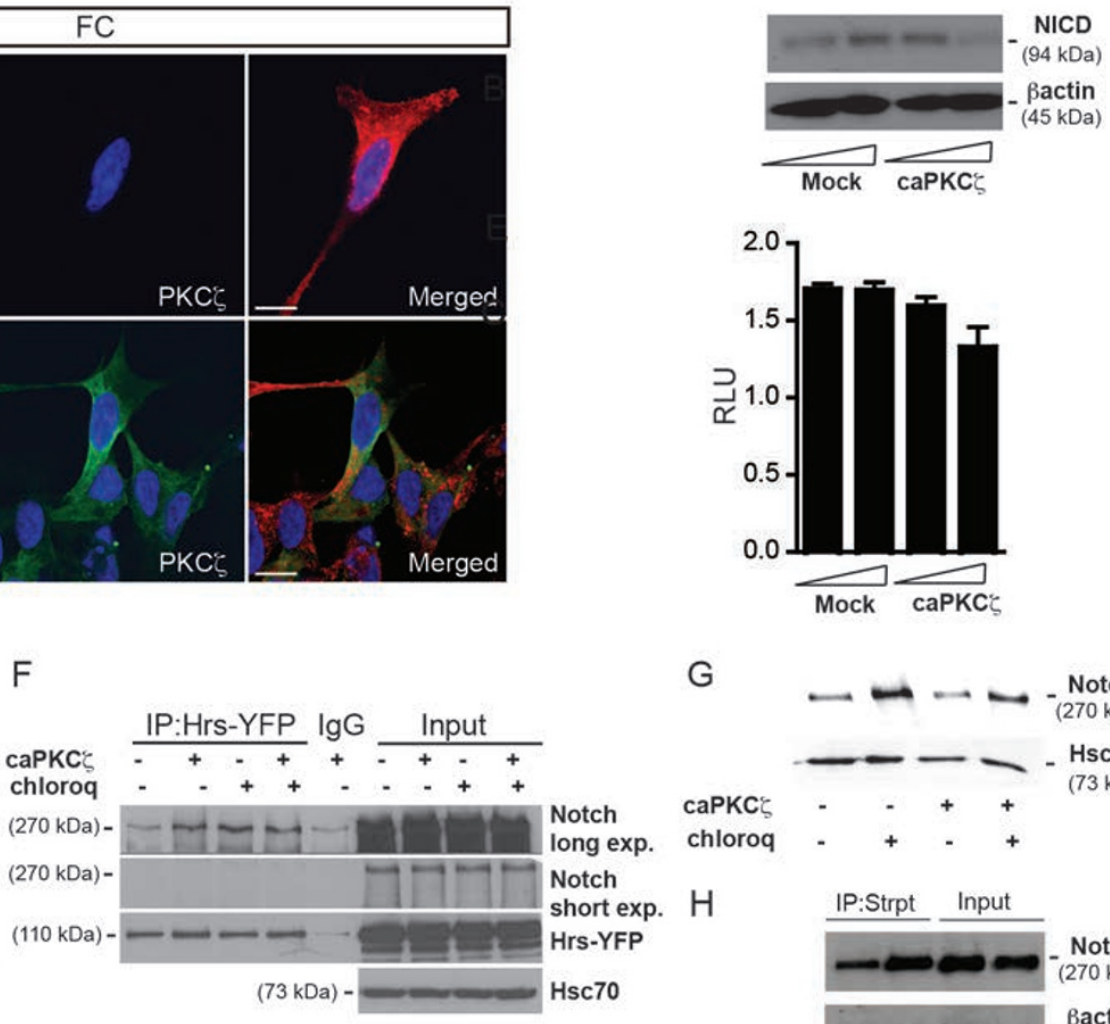

G

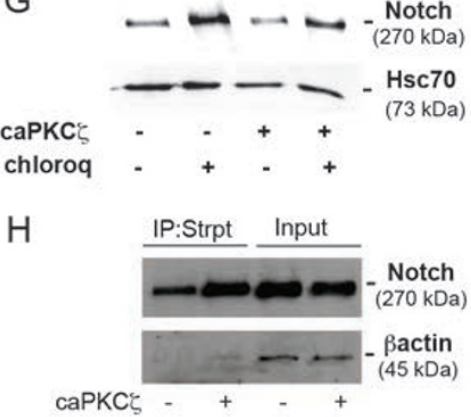


as the key $\mathrm{PKC} \zeta$ phosphorylation site in Notch1 allowed us to test the effects of phosphomimetic and phosphorylation-deficient mutants of Notch1, which were congruent with enhancement and reduction of PKC $\zeta$ activity, respectively. Indeed, expression of the phosphomimetic Notch $1 \Delta \mathrm{E}^{\mathrm{S} 1791 \mathrm{E}}$ resulted in re-localization of Notch immunoreactivity from intracellular vesicles to the nucleus, enhanced NICD production and Notch signaling. In contrast, the phosphorylation-deficient Notch $1 \Delta \mathrm{E}^{\mathrm{S} 1791 \mathrm{~A}}$ yielded the opposite phenotype, i.e., accumulation in intracellular vesicles, less NICD production and Notch signaling. The notion that Notch processing is actively controlled in the late endosome compartment is corroborated by earlier reports that mutations in ESCRT proteins, which regulate endocytic sorting and further transition to lysosomes, led to endosomal accumulation of Notch and enhanced Notch signaling [53, 54].

In the non-activated state, $\mathrm{PKC} \zeta$ affects Notch receptor routing in a different manner. Notch is shifted from the cell surface to intracellular vesicles. The observation that PKC $\zeta$ was associated with the full-length Notch1 prior to $\gamma$-secretase cleavage supports the view that $\mathrm{PKC} \zeta$ can control Notch in the non-activated state. It is interesting to note that membrane-tethering of the receptor appeared to be a prerequisite for $\mathrm{PKC} \zeta$ binding and phosphorylation; an NICD without a transmembrane domain did not interact with $\mathrm{PKC} \zeta$, and was also not phosphorylated. Increased internalization of Notch1 by PKC $\zeta$ in the non-activated state is further supported by an enhanced interaction of Notch1 with Hrs, a protein localized in early endosomes/multivesicular bodies. While it may appear reasonable to surmise that internalization of Notch receptors by PKC $\zeta$ would be associated with increased signaling, we did not observe an increase in the amount of NICD or in the immediate downstream signaling. In the light of increased receptor internalization, we unexpectedly did not observe a decrease in biotinylation of Notch receptors at cell surface upon expression of a constitutively active PKC $\zeta$. We currently cannot explain this finding, but the data raise the intriguing possibility that non-activated Notch receptors may be recycled back to the cell surface from endosomes rather than being degraded in lysosomes. PKC $\zeta$ may then shift the balance towards the endosomal localization at the expense of cell surface localization rather than blocking the recycling process per se. This would be compatible with the data on Notch1 localization and Hrs interaction, and a continued recycling may also explain why cell surface labeling of Notch1 was not reduced and why there was no increase in lysosomal degradation.

Different from other proteins known to affect Notch intracellular routing, $\mathrm{PKC} \zeta$ acts at two distinct steps in receptor trafficking depending on the activation state of Notch, i.e., shifting Notch from cell surface to early endosomes in the non-activated state and from late endosomes to nucleus in the activated state. The distinct activation-dependent outcomes may explain why endocytosis in certain situations enhances Notch signaling, while in other settings it downregulates Notch signaling [4-12]. Our data show that PKC $\zeta$ not only modulates Notch1 localization and signaling activity, but also exerts an effect on Notch-controlled differentiation processes. Inhibition of PKC $\zeta$ abrogated Notch1-mediated block of differentiation in the developing CNS. Ossipova et al. [40] have

Figure 7 aPKC regulates localization of Notch1 in the non-activated state. (A) Representative microscopy images showing localization of Notch1 and PKC $\zeta$ in a Notch signaling off state. 293FLN1 cells were cultured sparsely and transfected with caPKC $\zeta$ or control vector. The cells were stained with antibodies against Notch1 (green) and PKC $\zeta$ (red), and counterstained with DAPI. (B) Representative microscopy images showing localization of Notch1 and $\mathrm{PKC} \zeta$ in $\mathrm{C} 2 \mathrm{C} 12$ cells expressing fulllength Notch1 transfected with caPKC $\zeta$ or empty vector. The cells were stained with antibodies against Notch1 and PKC $\zeta$, and counterstained with DAPI. (C) Quantification of the internalization of the receptor using a fluorescently labeled recombinant peptide Jagged1 extracellular domain which binds to the extracellular domain of Notch. Quantification was performed by flow cytometry. The number above the bars denotes the percentage of positive cells, i.e., cells which have internalized the fluorescent peptide and show positive fluoresence. These cells were gated and MFI denotes mean fluorescence intensity, i.e., mean intensity per cell within the gated population (in this case $79.8 \%$ of mock and $68.4 \%$ of caPKC $\zeta$ were gated). (D) Upper, western blot using an antibody against NICD in 293FLN1 cells transfected with increasing amounts of caPKC $\zeta$. Lower, Notch signaling activity in 293FLN1 cells transfected with increasing amounts of PKC $\zeta$ and a control vector. (E) Immunoprecipitation using an antibody against Notch1 in HeLa cells transfected with Notch1 $\triangle \mathrm{E}, \mathrm{HA}$-tagged ubiquitin (Ub-HA) and caPKC $\zeta$, caPKC ${ }_{\imath}$ or empty vector. The cells were subjected to a 24-h treatment with chloroquine prior to harvesting. Immunoblotting was performed with an antibody recognizing the HA-tag, for the input an antibody against Notch1 was used. (F) Immunoprecipitation with an antibody against the endosome-associated ubiquitin-binding protein Hrs in HeLa cells transfected with Notch $1 \Delta \mathrm{E}$ and caPKC $\zeta$ or empty vector. Cells were treated with chloroquine or vehicle control $24 \mathrm{~h}$ prior to harvesting. Immunoblotting was performed using an antibody against Notch1. (G) Western blotting showing Notch1 levels in 293FLN1 cells transfected with caPKC $\zeta$ or empty vector and treated with chloroquine or vehicle control $24 \mathrm{~h}$ prior to harvesting. $\mathbf{( H )}$ Immunoblot using a Notch1 antibody on streptavidin immunoprecipitates of biotin-labeled surface Notch1. Scale bars in A and B, $10 \mu \mathrm{m}$. 
previously demonstrated that $\mathrm{PKC} \zeta$ suppresses neuronal differentiation, which is in line with the results presented here. They showed that PKC negatively regulates PAR1, which in turn blocks the function of the E3 ubiquitin ligase Mindbomb, thereby enhancing the level of D111 ligands. While this can clearly lead to blocked neurogenesis, it is mechanistically distinct from the direct action of aPKC on Notch1 presented here.

In $\mathrm{C} 2 \mathrm{C} 12$ myoblasts, $\mathrm{PKC} \zeta$ enhanced Notch signaling, in keeping with a Notch signaling-promoting role of $\mathrm{PKC} \zeta$ when Notch signaling is engaged, and reduced differentiation to MHC-positive myotubes under differentiation-promoting conditions. Conversely, pharmacological inhibition of $\mathrm{PKC} \zeta$ led to precocious differentiation of myotubes and reduced levels of NICD. Similarly, a phosphodeficient Notch $1 \Delta \mathrm{E}$ increased the proportion of differentiated cells, as compared to wild-type Notch $1 \Delta \mathrm{E}$. These observations add to an emerging view of PKC $\zeta$ as an important regulator of cell differentiation in various settings $[40,55,56]$. The influence of PKC $\zeta$ on differentiation is multifaceted and we have previously demonstrated that $\mathrm{PKC} \zeta$ is required for fusion and terminal differentiation of myoblasts through the regulation of Caspase- 3 and Cdk5/p35 kinase [39]. It is interesting to note that in the present study, PKC $\zeta$ plays a differentiation-inhibiting role at the earlier stages of myogenic differentiation when Notch signaling is active.

In conclusion, the data presented here shed new light on Notch receptor intracellular routing and identifies $\mathrm{PKC} \zeta$ as a key controller of distinct steps in Notch receptor trafficking. In addition to providing a new regulatory mechanism for Notch signaling, the newly discovered link between aPKC and Notch may also be important to be taken into consideration when pharmacologically intervening with aPKC function in diseases, as such approaches may inadvertently impinge on Notch signaling.

\section{Materials and Methods}

\section{Cell culture}

Mouse $\mathrm{C} 2 \mathrm{C} 12$ myoblasts, human embryonic kidney 293 cells (293 HEK) and cervical cancer HeLa cells were grown in Dulbecco's modified Eagle's medium (DMEM), supplemented with $10 \%$ fetal bovine serum (FBS), $2 \mathrm{mM}$ glutamine, penicillin (100 $\mathrm{U} / \mathrm{ml})$ and streptomycin $(100 \mu \mathrm{g} / \mathrm{ml})$. Differentiation of C2C12 myoblasts was induced by replacing the cell culture medium with differentiation medium (DMEM supplemented with 1\% FBS, 2 $\mathrm{mM}$ glutamine, penicillin $(100 \mathrm{U} / \mathrm{ml})$ and streptomycin $(100 \mu \mathrm{g} /$ $\mathrm{ml})$ ). The $\gamma$-secretase inhibitor DAPT was used at a concentration of $5 \mu \mathrm{g} / \mathrm{ml}$. The concentrations of lysosomal inhibitor chloroquine and the proteasomal inhibitor MG132 were $20 \mu \mathrm{M}$. The dynamin inhibitor Dynasore was used at a concentration of $80 \mu \mathrm{M}$. To inhibit PKC $\zeta$ activity, cells were grown in the presence of $20 \mu \mathrm{M}$ pseudosubstrate inhibitor peptide (PS; Myr-SIYRRGARRWRKL) or control scrambled peptide (Scr-P; Myr-RLYRKRIWRSAGR; MilleGen Prologue Biotech, Labege Cedex, France). Alternatively, PKC $\zeta$ was downregulated by siRNA. Note that the timing of the treatment/downregulation was adjusted to inhibit $\mathrm{PKC} \zeta$ activity under conditions of active Notch signaling.

\section{In vivo analysis of chick CNS development}

DNA constructs were electroporated into the caudal neural tube of HH stage 10 chick embryos. After 24-40 h, embryos were fixed and processed for immunohistochemistry. In the cohort of embryos in which $\mathrm{PKC} \zeta$ activity was to be inhibited, $20 \mu \mathrm{M}$ pseudosubstrate inhibitor peptide was included in the DNA mix prior to electroporation. Images were acquired with a Zeiss Axiovert microscope fitted with a LSM5 Exciter confocal unit. The objectives used were Plan Apochromat $10 \times$ and $20 \times$ objectives with apertures of 0.45 and 0.8 , respectively. The Zeiss LSM Imaging software was utilized for image acquisition. Images were processed in Adobe Photoshop (AS5). Contrast enhancement of the images was performed utilizing the tool "Levels" in AS5. The images of the different experimental groups were processed in an identical manner. The fluorochromes used were Alexa 555, and Alexa 647 from Life Technologies.

\section{Primary mouse myoblast culture}

Cultures of primary myoblasts were established from the limb skeletal muscles of two-day-old FVB/N mice. Muscle tissue was minced and enzymatically digested by incubation in $0.2 \%$ (wt/vol) type XI collagenase (Roche Diagnostics, Basel, Switzerland) and $0.1 \%$ (wt/vol) trypsin at $37{ }^{\circ} \mathrm{C}$ for $45 \mathrm{~min}$. The resulting slurry was filtered to remove large pieces of tissue and rinsed with growth medium as follows: Ham's F-10 (Sigma-Aldrich, St Louis, MO, USA) supplemented with $15 \%$ (vol/vol) FBS, $2 \mathrm{mM}$ glutamine, penicillin $\mathrm{G}(100 \mathrm{U} / \mathrm{ml}) /$ streptomycin $(100 \mu \mathrm{g} / \mathrm{ml})$ and $2.5 \mathrm{ng} / \mathrm{ml}$ $\beta$-FGF (fibroblast growth factor). Cells were centrifuged at $1000 \times$ $g$ for $5 \mathrm{~min}$, resuspended in growth medium and seeded into tissue culture dishes. After attainment of $80 \%$ confluence, differentiation was induced by replacing growth medium with differentiation medium as follows: DMEM supplemented with $2 \%$ (vol/vol) FBS, 2 $\mathrm{mM}$ glutamine and penicillin $\mathrm{G}(100 \mathrm{U} / \mathrm{ml}) /$ streptomycin $(100 \mu \mathrm{g} /$ $\mathrm{ml})$.

\section{Transfection}

For transfection, HeLa and 293 HEK cells were pelleted and resuspended in Opti-MEM (Invitrogen) together with the desired plasmid and electroporated at $220 \mathrm{~V}$ and $975 \mu \mathrm{F}$. The transfected cells were plated and harvested after $24 \mathrm{~h}$ for further analysis. $\mathrm{C} 2 \mathrm{C} 12$ myoblasts were transfected using jetPEI transfection reagent (Polyplus transfections) according to the manufacturer's instructions.

\section{Western blotting}

Proteins were separated by SDS-PAGE and transferred to a Protran nitrocellulose membrane (Perkin Elmer) using a wet transfer apparatus (Amersham Biosciences). Non-specific binding was blocked by incubating the membranes in $5 \%$ non-fat dry milk at room temperature (RT) for $1 \mathrm{~h}$. Membranes were incubated with primary antibody overnight at $4{ }^{\circ} \mathrm{C}$, followed by incubation with a secondary antibody coupled to horseradish peroxidase for $1 \mathrm{~h}$ at RT. Proteins were detected using Western Lightning ${ }^{\circledR}$ Plus- 
ECL Enhanced chemiluminescence substrate (Perkin Elmer, MA, USA), according to the manufacturer's instructions.

\section{Antibodies and constructs}

The following antibodies were used: PKC (C20 rabbit) (Santa Cruz Biotechnology), $\beta$-actin (rabbit) (Cell Signaling Technology), Cleaved Notch1 (rabbit Val1744) (Cell Signaling Technology), Notch1 (Cleaved-Val-1744 rabbit) (Sigma Aldrich), HA.11 (mouse) (Covance), Hsc70 (rat 1B5) (StressGen), GFP (rabbit JL-8) (Clontech), $\alpha$-GFP (rabbit) (Invitrogen), Lamp1 (mouse H4A3) (Abcam), Myosin heavy chain (rabbit H-300) (Santa Cruz Biotechnology), Notch1 (C20 rabbit for western blot and goat for IP) (Santa Cruz Biotechnology). Fluorescent secondary antibodies: Alexa Fluor 555 donkey anti-goat IgG, Alexa Fluor 488 donkey anti-goat IgG, Alexa Fluor 488 donkey anti-rabbit IgG, Alexa Fluor 546 donkey anti-rabbit IgG, Alexa Fluor 488 Donkey anti-goat IgG 488 (Invitrogen). GFP-Rab5, Lamp1-GFP and GFP-Rab7 were kind gifts from Dr J Ivaska (VTT, Turku, Finland), GFP-Fyve and GFPEEA1 have been previously described. The table in Supplementary information, Figure S2 denotes the proteolytic processing and the respective products of endogenous Notch1 in the pathway, the different Notch1 constructs and their immunoreactivity.

\section{Immunoprecipitation}

Cells were lysed in immunoprecipitation buffer $(50 \mathrm{mM}$ Tris, pH 8.0, $150 \mathrm{mM} \mathrm{NaCl}, 1 \% \mathrm{NP}-40,0.5 \%$ deoxycholic acid, $0.05 \%$ SDS, 5 mM EDTA, 5 mM EGTA and protease inhibitor (Complete protease inhibitor cocktail, Roche)) for $30 \mathrm{~min}$ on ice, followed by centrifugation at $15000 \times g$ for $10 \mathrm{~min}$ at $4{ }^{\circ} \mathrm{C}$. Lysates were precleared by incubating with a small amount of protein $\mathrm{G}$ dynabeads (Invitrogen) on rotation at $4{ }^{\circ} \mathrm{C}$ for $1 \mathrm{~h}$. Immunoprecipitation was conducted with the denoted antibodies (C20 goat IgG for Notch and cleaved Notch1 (Val1744) for NICD) overnight at $4{ }^{\circ} \mathrm{C}$. Immunocomplexes were captured by addition of protein $\mathrm{G}$ dynabeads and incubation for $2 \mathrm{~h}$ at $4{ }^{\circ} \mathrm{C}$, washed three times with immunoprecipitation buffer and resuspended in Laemmli Sample buffer for analysis.

Alternatively, cells were lysed in immunoprecipitation buffer (50 mM HEPES, pH 7.4, $140 \mathrm{mM} \mathrm{NaCl}, 5 \mathrm{mM} \mathrm{MgCl}{ }_{2}, 5 \mathrm{mM}$ EGTA, $0.4 \%$ (vol/vol) NP-40, $10 \mathrm{mM}$ pyrophosphate, $5 \mathrm{mM}$ sodium orthovanadate and a protease inhibitor cocktail (Roche Diagnostics) for $30 \mathrm{~min}$ on ice followed by centrifugation at $12000 \times$ $g$ for $10 \mathrm{~min}$ at $4{ }^{\circ} \mathrm{C}$. Protein concentration was measured by the Bradford assay, and $800 \mu \mathrm{g}$ of each lysate was precleared using Sepharose beads, for $45 \mathrm{~min}$, followed by immunoprecipitation with the indicated antibodies. Immunocomplexes were captured on protein G-Sepharose beads, washed four times in $20 \mathrm{mM}$ HEPES, pH 7.4, 2 mM EGTA, $100 \mathrm{mM} \mathrm{NaCl}, 0.4 \%$ (vol/vol) NP-40, and $1 \mathrm{mM}$ dithiothreitol (DTT), and finally resuspended in Laemmli sample buffer.

\section{Immunocytochemistry}

Cells grown on cover slips were fixed in 3\% paraformaldehyde and permeabilized with $0.1 \%$ Triton X-100 in PBS for 5 min at RT. Non-specific binding sites were blocked by incubation in $3 \%$ bovine serum albumin (BSA) in PBS with $0.05 \%$ Triton X-100 for 30-60 min at RT. Cells were stained with primary antibodies overnight at $4{ }^{\circ} \mathrm{C}$ or $2 \mathrm{~h}$ at RT, after which coverslips were rinsed three times with PBS and stained for 40-60 min with fluorescence tag-labeled secondary antibodies. Cells were counterstained with DAPI and washed three times in PBS before mounting with Prolong Gold (Invitrogen). Images were collected using a Zeiss LSM510 META laser scanning microscope. Images were processed in Adobe Photoshop (CS5). Contrast enhancement of the images was performed utilizing the tool "Levels" in AS5. The images of the different experimental groups were processed in an identical manner. The fluorochromes used were Alexa 488, 555 and Alexa 647 from Life Technologies.

\section{Luciferase reporter assay}

Cells stably expressing the full-length Notch receptor were transfected with $12 \times$ CSL-luc and CMV- $\beta$-galactosidase using electroporation. Depending on the experiment, cells were also co-transfected with Notch $1 \Delta \mathrm{E}$, Notch $1 \Delta \mathrm{E}^{\mathrm{S} 1791 \mathrm{~A}}$, Notch $1 \Delta \mathrm{E}^{\mathrm{S} 1769 \mathrm{E}}$, NICD and caPKC $\zeta$. Twenty-four hours later, the cells were lysed in Cell culture lysis reagent (Promega) and analyzed for luciferase activity using a Luciferase assay system (Promega) with a Luminoskan ascent microplate luminometer (Thermo Scientific). $\beta$-galactosidase activity is measured using a Multiskan ascent (Thermo Scientific).

\section{Activation of Notch signaling by immobilized recombinant Notch ligands \\ Cell culture plates were coated with $50 \mu \mathrm{g} / \mathrm{ml}$ Protein G (Zymed)} in PBS at RT overnight. The plates were washed three times with PBS and blocked with $10 \mathrm{mg} / \mathrm{ml}$ BSA in PBS for $2 \mathrm{~h}$ at RT. The blocked plates were washed three times with PBS and incubated with recombinant Jagged1-FC chimera (R\&D Systems) or Fc-IgG (Jackson ImmunoResearch) at concentrations of $0.5 \mu \mathrm{g} / \mathrm{ml}$ in $0.1 \%$ $\mathrm{BSA} / \mathrm{PBS}$ for $2 \mathrm{~h}$ at RT. Alternatively, conditioned medium from 293 HEK cells expressing soluble D1l1 was used as a source for immobilized ligand. After final washing with PBS and cell culture medium, the cells were plated on the coated plates and harvested for analysis $24 \mathrm{~h}$ later.

\section{Ubiquitylation assay}

The cells were pelleted and suspended in ice-cold PBS. Preheated $1 \%$ SDS in PBS was added and the samples were boiled for $7 \mathrm{~min}$. The samples were further suspended in $1 \%$ Triton X-100, $0.5 \%$ BSA in PBS and sonicated, followed by centrifugation at 10 $000 \times g$ for $10 \mathrm{~min}$ at $4{ }^{\circ} \mathrm{C}$. Finally, the samples were immunoprecipitated with the indicated antibodies as described previously.

\section{Biotinylation assay}

Cells were placed on ice and washed with cold PBS. Surface proteins were labeled with $0.5 \mathrm{mg} / \mathrm{ml}$ EZ-link sulfo-NHS-SS-biotin in PBS for $30 \mathrm{~min}$ at $4{ }^{\circ} \mathrm{C}$. The cells were washed three times with cold $0.1 \mathrm{M}$ glycine in PBS, followed by three washes with cold PBS. The cells were pelleted by scraping in immunoprecipitation buffer containing protease inhibitors and incubated on ice for $10 \mathrm{~min}$. The lysates were centrifuged at $15000 \mathrm{rpm}$ for $10 \mathrm{~min}$ at $4{ }^{\circ} \mathrm{C}$ and the supernatant was collected. EZ-link sulfo-NHS-SS-biotin-labeled proteins were immunoprecipitated by incubating with Streptavidine agarose beads at $4{ }^{\circ} \mathrm{C}$ on rotation. The pellets were washed three times with immunoprecipitation buffer before resuspension in Laemmli Sample buffer for analysis by SDS-PAGE.

\section{In vitro phosphorylation and kinase activity assays}

In vitro phosphorylation assays were performed using immunoprecipitated Notch as substrates. Cell lysates were incubated 
with Notch antibody (C20) for $1 \mathrm{~h}$ and subsequently with protein G-Sepharose beads for $45 \mathrm{~min}$. Immunoprecipitates were washed for four times in $50 \mathrm{mM}$ HEPES (pH 7.4), 5 mM EDTA, $125 \mathrm{mM}$ $\mathrm{NaCl}, 0.2 \%(\mathrm{v} / \mathrm{v}) \mathrm{NP}-40$ and $1 \mathrm{mM}$ DTT, and twice with $50 \mathrm{mM}$ HEPES (pH 7.4), $25 \mathrm{mM} \mathrm{NaCl}$ and $1 \mathrm{mM}$ DTT, and resuspended in PKC $\zeta$ kinase buffer (50 mM HEPES, pH 7.4, 1 mM EDTA, 1 mM DTT, $10 \mathrm{mM} \mathrm{MgCl}_{2}$ ) with $200 \mu \mathrm{M}$ unlabeled ATP, $10 \mu \mathrm{Ci}$ $\left(\gamma_{32} \mathrm{P}\right)$-ATP and $50 \mathrm{ng}$ recombinant PKC $\zeta$ (Upstate Biotechnology, New York, USA). The reaction was allowed to proceed for $30 \mathrm{~min}$ at $32{ }^{\circ} \mathrm{C}$. Reactions were stopped by addition of Laemmli sample buffer and boiling for $5 \mathrm{~min}$. Gels were stained with Coomassie Blue, dried and subjected to autoradiography. As loading controls, $8 \mu 1$ aliqoutes of immunoprecipitates were subjected to SDSPAGE, transferred to nylon membranes, stained with Red Ponceau and visualized using the ECL Western blotting kit (Amersham). Identification of phosphorylation sites by mass spectrometry is described in Supplementary information, Figure S3.

\section{Receptor internalization by FACS}

293FLN1 cells were transfected with $\mathrm{caPKC} \zeta$ or control vector and plated on 12-well plates. The following day recombinant rat Jagged1-FC chimera (R\&D systems, Cat\# 599-JG) $(1 \mu \mathrm{g} / \mathrm{ml})$ and Alexa Fluor 488 goat anti-human IgG (Invitrogen, Cat\# A11013) $(1: 200)$ were diluted in sterile PBS and incubated on rotation at 4 ${ }^{\circ} \mathrm{C}$ for $1 \mathrm{~h}$. Simultaneously, the cells were blocked with DMEM containing $10 \%$ goat serum and $1 \% \mathrm{BSA}$ for $45 \mathrm{~min}$ at $37{ }^{\circ} \mathrm{C}$. The Jagged FC-Alexa 488 solution was further diluted in blocking solution at a ratio of 1:5 and this solution was added to the cells, followed by incubation at $37^{\circ} \mathrm{C}$ for $2 \mathrm{~h}$. The cells were then detached, centrifuged (450× $\mathrm{g}, 5 \mathrm{~min})$ and quenched with $200 \mu \mathrm{g} /$ $\mathrm{ml}$ trypan blue in PBS for 5 min at RT. Next, the cells were centrifuged again and excess trypan blue was removed. The cells were finally resuspended in PBS and analyzed by FACS.

\section{Acknowledgments}

This work was supported by Academy of Finland (CS, SYI), Center of Excellence in Cell stress and Molecular Aging, Åbo Akademi (DA), Turku Graduate School for Biomedical Sciences (MS), the Swedish Cancer Society, the Swedish Research Council (DBRM, StratRegen and Project Grant), Karolinska Institute (BRECT, Theme Center in Regenerative Medicine and a Distinguished Professor Award to UL). We are grateful to Helena Saarento for technical assistance. We thank the Cell Imaging Core at Turku Centre for Biotechnology and the proteomics facility of the MRC Protein Phosphorylation Unit, University of Dundee.

\section{References}

1 Andersson ER, Sandberg R, Lendahl U. Notch signaling: simplicity in design, versatility in function. Development 2011; 138:3593-3612.

2 Kopan R, Ilagan MX. The canonical Notch signaling pathway: unfolding the activation mechanism. Cell 2009; 137:216-233.

3 Yamamoto S, Charng W-L, Bellen HJ. Endocytosis and intracellular trafficking of Notch and its ligands. Curr Top Dev Biol 2010; 92:165-200.
4 Gupta-Rossi N, Six E, LeBail O, et al. Monoubiquitination and endocytosis direct gamma-secretase cleavage of activated Notch receptor. J Cell Biol 2004; 166:73-83.

5 Nichols JT, Miyamoto A, Weinmaster G. Notch signalingconstantly on the move. Traffic 2007; 8:959-969.

6 Seugnet L, Simpson P, Haenlin M. Requirement for dynamin during Notch signaling in Drosophila neurogenesis. Dev Biol 1997; 192:585-598.

7 Vaccari T, Lu H, Kanwar R, Fortini ME, Bilder D. Endosomal entry regulates Notch receptor activation in Drosophila melanogaster. J Cell Biol 2008; 180:755-762.

8 Berdnik D, Török T, González-Gaitán M, Knoblich JA. The endocytic protein alpha-Adaptin is required for numb-mediated asymmetric cell division in Drosophila. Dev Cell 2002; 3:221-231.

9 Childress JL, Acar M, Tao C, Halder G. Lethal giant discs, a novel C2-domain protein, restricts notch activation during endocytosis. Curr Biol 2006; 16:2228-2233.

10 Gallagher CM, Knoblich JA. The conserved c2 domain protein lethal (2) giant discs regulates protein trafficking in Drosophila. Dev Cell 2006; 11:641-653.

11 Shaye DD, Greenwald I. Endocytosis-mediated downregulation of LIN-12/Notch upon Ras activation in Caenorhabditis elegans. Nature 2002; 420:1-5.

12 Sorensen EB, Conner SD. $\gamma$-secretase-dependent cleavage initiates notch signaling from the plasma membrane. Traffic 2010; 11:1234-1245.

13 Gupta-Rossi N, Ortica S, Meas-Yedid V, et al. The adaptorassociated kinase 1, AAK1, is a positive regulator of the Notch pathway. J Biol Chem 2011; 286:18720-18730.

14 Vaccari T, Duchi S, Cortese K, Tacchetti C, Bilder D. The vacuolar ATPase is required for physiological as well as pathological activation of the Notch receptor. Development 2010; 137:1825-1832.

15 Tagami S, Okochi M, Yanagida K, et al. Regulation of Notch signaling by dynamic changes in the precision of S3 cleavage of Notch-1. Mol Cell Biol 2008; 28:165-176.

16 Yan Y, Denef N, Schüpbach T. The vacuolar proton pump, VATPase, is required for notch signaling and endosomal trafficking in Drosophila. Dev Cell 2009; 17:387-402.

17 Moretti J, Chastagner P, Gastaldello S, et al. The translation initiation factor $3 \mathrm{f}$ (eIF3f) exhibits a deubiquitinase activity regulating Notch activation. PLoS Biol 2010; 8:e1000545.

18 Mukherjee A, Veraksa A, Bauer A, Rosse C, Camonis J, Artavanis-Tsakonas S. Regulation of Notch signalling by nonvisual beta-arrestin. Nat Cell Biol 2005; 7:1191-1201.

19 Sestan N. Contact-dependent inhibition of cortical neurite growth mediated by notch signaling. Science 1999; 286:741746.

20 Wilkin M, Tongngok P, Gensch N, et al. Drosophila HOPS and AP-3 complex genes are required for a Deltex-regulated activation of notch in the endosomal trafficking pathway. Dev Cell 2008; 15:762-772.

21 Fortini ME, Bilder D. Endocytic regulation of Notch signaling. Curr Opin Genet Dev 2009; 19:323-328.

22 McGill MA, Dho SE, Weinmaster G, McGlade CJ. Numb regulates post-endocytic trafficking and degradation of Notch1. $J$ Biol Chem 2009; 284:26427-38.

23 Le Borgne R, Bardin A, Schweisguth F. The roles of receptor 
and ligand endocytosis in regulating Notch signaling. Development 2005; 132:1751-1762.

24 Bilder D. Epithelial polarity and proliferation control: links from the Drosophila neoplastic tumor suppressors. Genes Dev 2004; 18:1909-1925.

25 Galli M, Muñoz J, Portegijs V, et al. aPKC phosphorylates NuMA-related LIN-5 to position the mitotic spindle during asymmetric division. Nat Cell Biol 2011; 13:1132-1138.

26 Atwood SX, Prehoda KE. aPKC phosphorylates Miranda to polarize fate determinants during neuroblast asymmetric cell division. Curr Biol 2009; 19:723-729.

27 Lee CY, Andersen RO, Cabernard C, et al. Drosophila Aurora-A kinase inhibits neuroblast self-renewal by regulating aPKC/Numb cortical polarity and spindle orientation. Genes Dev 2006; 20:3464-3474.

28 Nishimura T, Kaibuchi K. Numb controls integrin endocytosis for directional cell migration with aPKC and PAR-3. Dev Cell 2007; 13:15-28.

29 Rosse C, Formstecher E, Boeckeler K, et al. An aPKCexocyst complex controls paxillin phosphorylation and migration through localised JNK1 activation. PLoS Biol 2009; 7:e1000235.

30 Zhou P, Alfaro J, Chang EH, Zhao X, Porcionatto M, Segal R A. Numb links extracellular cues to intracellular polarity machinery to promote chemotaxis. Dev Cell 2011; 20:610-622.

31 Cui S, Otten C, Rohr S, Abdelilah-Seyfried S, Link BA. Analysis of aPKClambda and aPKCzeta reveals multiple and redundant functions during vertebrate retinogenesis. Mol Cell Neurosci 2007; 34:431-444.

32 McCaffrey LM, Macara IG. The Par3/aPKC interaction is essential for end bud remodeling and progenitor differentiation during mammary gland morphogenesis. Genes Dev 2009; 23:1450-1460.

33 Tabler JM, Yamanaka H, Green JB. PAR-1 promotes primary neurogenesis and asymmetric cell divisions via control of spindle orientation. Development 2010; 137:2501-2505.

34 Williams SE, Beronja S, Pasolli HA, Fuchs E. Asymmetric cell divisions promote Notch-dependent epidermal differentiation. Nature 2011; 470:353-358.

35 Georgiou M, Marinari E, Burden J, Baum B. Cdc42, Par6, and aPKC regulate Arp2/3-mediated endocytosis to control local adherens junction stability. Curr Biol 2008; 18:16311638.

36 Georgiou M, Baum B. Polarity proteins and Rho GTPases cooperate to spatially organise epithelialactin-based protrusions. J Cell Sci 2010; 123:1389-1398.

37 Leibfried A, Fricke R, Morgan MJ, Bogdan S, Bellaiche Y. Drosophila Cip4 and WASp define a branch of the Cdc42Par6-aPKC pathway regulating E-cadherin endocytosis. Curr Biol 2008; 18:1639-1648.

38 Sato K, Watanabe T, Wang S, et al. Numb controls E-cadherin endocytosis through p120 catenin with aPKC. Mol Biol Cell
2011; 22:3103-3119.

39 Thonel D, Ferraris SE, Pallari H, et al. Protein kinase C regulates Cdk5/p25 signaling during. Mol Biol Cell 2010; 21:1423-1434.

40 Ossipova O, Ezan J, Sokol SY. PAR-1 phosphorylates Mind bomb to promote vertebrate neurogenesis. Dev Cell 2009; 17:222-233.

41 Balklava Z, Pant S, Fares H, Grant BD. Genome-wide analysis identifies a general requirement for polarity proteins in endocytic traffic. Nat Cell Biol 2007; 9:1066-1073.

42 Shivas JM, Morrison HA, Bilder D, Skop AR. Polarity and endocytosis: reciprocal regulation. Trends Cell Biol 2010; 20:445-452.

43 Holmberg J, Hansson E, Malewicz M, et al. SoxB1 transcription factors and Notch signaling use distinct mechanisms to regulate proneural gene function and neural progenitor differentiation. Development 2008; 135:1843-51.

44 Hansson EM, Teixeira AI, Gustafsson MV, et al. Recording Notch signaling in real time. Dev Neurosci 2006; 28:118-127.

45 Chapman G, Liu L, Sahlgren C, Dahlqvist C, Lendahl U. High levels of Notch signaling down-regulate Numb and Numblike. J Cell Biol 2006; 175:535-540.

46 Macia E, Ehrlich M, Massol R, Boucrot E, Brunner C, Kirchhausen T. Dynasore, a cell-permeable inhibitor of dynamin. Dev Cell 2006; 10:839-850.

47 Gulino A, Di Marcotullio L, Screpanti I. The multiple functions of Numb. Exp Cell Res 2010; 316:900-906.

48 Couturier L, Vodovar N, Schweisguth F. Endocytosis by Numb breaks Notch symmetry at cytokinesis. Nat Cell Biol 2012; 14:131-139.

49 Smith CA, Lau KM, Rahmani Z, et al. aPKC-mediated phosphorylation regulates asymmetric membrane localization of the cell fate determinant Numb. EMBO J 2007; 26:468-480.

50 Stenmark H. Rab GTPases as coordinators of vesicle traffic. Nat Rev Mol Cell Biol 2009; 10:513-525.

51 Dahlqvist C, Blokzijl A, Chapman G, et al. Functional Notch signaling is required for BMP4-induced inhibition of myogenic differentiation. Development 2003; 130:6089-6099.

52 Nofziger D, Miyamoto A, Lyons KM, Weinmaster G. Notch signaling imposes two distinct blocks in the differentiation of C2C12 myoblasts. Development 1999; 126:1689-1702.

53 Thompson BJ, Mathieu J, Sung HH, Loeser E, Rørth P, Cohen SM. Tumor suppressor properties of the ESCRT-II complex component Vps25 in Drosophila. Dev Cell 2005; 9:711-720.

54 Vaccari T, Bilder D. The Drosophila tumor suppressor vps 25 prevents nonautonomous overproliferation by regulating notch trafficking. Dev Cell 2005; 9:687-698.

55 Solecki DJ, Model L, Gaetz J, Kapoor TM, Hatten ME. Par6alpha signaling controls glial-guided neuronal migration. Nat Neurosci 2004; 7:1195-1203.

56 Solecki DJ, Govek EE, Tomoda T, Hatten ME. Neuronal polarity in CNS development. Genes Dev 2006; 20:2639-2647.

(Supplementary information is linked to the online version of the paper on the Cell Research website.) 